\title{
Dynamic rewiring of the human interactome by interferon signaling
}

Craig H. Kerr ${ }^{1,2,3+}{ }^{4}$, Michael A. Skinnider ${ }^{1+}$, Daniel D. T. Andrews ${ }^{2}$, Angel M. Madero ${ }^{1}$, Queenie W. T. Chan ${ }^{1}$, R. Greg Stacey ${ }^{1}$, Nikolay Stoynov ${ }^{1}$, Eric Jan ${ }^{2}$ and Leonard J. Foster ${ }^{1,2^{*}}$ (D)

\author{
* Correspondence: foster@msl.ubc. \\ ca \\ ${ }^{\dagger}$ Craig H. Kerr and Michael A. \\ Skinnider contributed equally to \\ this work. \\ ${ }^{1}$ Michael Smith Laboratories, \\ University of British Columbia, \\ Vancouver, BC V6T 1Z4, Canada \\ ${ }^{2}$ Department of Biochemistry and \\ Molecular Biology, University of \\ British Columbia, Vancouver, BC V6T \\ 1Z3, Canada \\ Full list of author information is \\ available at the end of the article
}

\begin{abstract}
Background: The type I interferon (IFN) response is an ancient pathway that protects cells against viral pathogens by inducing the transcription of hundreds of IFNstimulated genes. Comprehensive catalogs of IFN-stimulated genes have been established across species and cell types by transcriptomic and biochemical approaches, but their antiviral mechanisms remain incompletely characterized. Here, we apply a combination of quantitative proteomic approaches to describe the effects of IFN signaling on the human proteome, and apply protein correlation profiling to map IFN-induced rearrangements in the human protein-protein interaction network.
\end{abstract}

Results: We identify $>$ 26,000 protein interactions in IFN-stimulated and unstimulated cells, many of which involve proteins associated with human disease and are observed exclusively within the IFN-stimulated network. Differential network analysis reveals interaction rewiring across a surprisingly broad spectrum of cellular pathways in the antiviral response. We identify IFN-dependent protein-protein interactions mediating novel regulatory mechanisms at the transcriptional and translational levels, with one such interaction modulating the transcriptional activity of STAT1. Moreover, we reveal IFN-dependent changes in ribosomal composition that act to buffer IFN-stimulated gene protein synthesis.

Conclusions: Our map of the IFN interactome provides a global view of the complex cellular networks activated during the antiviral response, placing IFN-stimulated genes in a functional context, and serves as a framework to understand how these networks are dysregulated in autoimmune or inflammatory disease.

Keywords: Interferon, Proteomics, Interferon-stimulated gene, Innate immunity, Protein correlation profiling, Interactome, Protein complexes

\section{Background}

Type I interferons (IFNs) are an evolutionary ancient family of cytokines that play a central role in the immune response to viral pathogens [1]. IFN synthesis and secretion are triggered in response to pathogen detection by intra- and extracellular receptors, leading to the activation of multiple defense mechanisms via the transcription of IFNstimulated genes (ISGs) [2]. These ISGs contribute to the establishment of a cellintrinsic antiviral state in infected and neighboring cells, while also modulating the

(c) The Author(s). 2020 Open Access This article is licensed under a Creative Commons Attribution 4.0 International License, which permits use, sharing, adaptation, distribution and reproduction in any medium or format, as long as you give appropriate credit to the original author(s) and the source, provide a link to the Creative Commons licence, and indicate if changes were made. The images or other third party material in this article are included in the article's Creative Commons licence, unless indicated otherwise in a credit line to the material. If material is not included in the article's Creative Commons licence and your intended use is not permitted by statutory regulation or exceeds the permitted use, you will need to obtain permission directly from the copyright holder. To view a copy of this licence, visit http://creativecommons.org/licenses/by/4.0/. The Creative Commons Public Domain Dedication waiver (http://creativecommons.org/publicdomain/zero/1.0/) applies to the data made available in this article, unless otherwise stated in a credit line to the data. 
development of innate and adaptive immune responses [3]. Activation of the IFN response must be carefully regulated in order to strike a balance between effective pathogen clearance on the one hand and tissue damage or auto-inflammatory pathology on the other, as aberrant IFN signaling has been implicated in a range of autoimmune and neuropsychiatric diseases $[4,5]$.

In the canonical type I IFN signaling pathway, IFNs bind the heterodimeric IFNa receptor (IFNAR) complex, thereby activating the receptor-associated tyrosine kinases JAK1 and TYK2. In turn, these kinases phosphorylate the cytoplasmic STAT1 and STAT2 transcription factors. Translocation of STAT1 and STAT2 to the nucleus, followed by association with IRF9 to form the IFN-stimulated gene factor 3 (ISGF3) complex, activates ISG transcription. While some of these ISGs encode proteins with direct antiviral activity, many ISG products modulate parallel signaling pathways or encode additional transcription factors. Consequently, IFN stimulation induces a complex response that is not limited to a simple antiviral program, but instead activates a number of additional signaling pathways such as the MAPK cascade and the mTOR-AKTS6K axis, which contribute to ISG induction or the antiviral response more broadly [3]. Ultimately, this cascade results in substantial remodeling of mRNA processing, posttranslational modifications, metabolism, cellular trafficking, chromatin organization, and the cytoskeleton, among other processes [6].

A combination of unbiased transcriptome profiling [2, 7-9] and biochemical approaches [10-13] has identified hundreds of ISGs and, in some cases, elucidated their mechanism of action. Yet the functional roles of most ISGs as effectors of the innate immune response remain to be fully characterized. Furthermore, in view of the limited ability of mRNA levels to predict cellular protein abundance [14, 15], the degree to which IFN-induced changes in transcriptional activity ultimately manifest at the level of the proteome remains incompletely understood. A complete understanding of the IFN signaling repertoire would include a direct interrogation of the complex network of interacting proteins that mediate the type I IFN response, beyond those with a direct role in restricting viral replication. However, experimentally mapping the cellular interaction network in differential and physiologically relevant contexts at the proteome scale represents a long-standing challenge [16].

Here, we apply a combination of quantitative proteomic approaches to chart the molecular landscape of type I IFN signaling, culminating in the use of protein correlation profiling (PCP) [17] to map interferon-induced rearrangements in the human interactome. The resulting protein-protein interaction network, encompassing over 26,000 interactions, reveals widespread rewiring of physical interactions and places known ISGs in an IFN-dependent functional context. We find evidence that an evolutionarily conserved subset of ISGs are induced to physically interact in response to IFN- $\beta$ stimulation, and experimentally validate the role of one such interaction in modulating STAT1-mediated transcription. We develop statistical methods for differential network analysis to characterize interactome rewiring at the functional level, leading us to identify alterations in ribosome composition induced by interferon signaling that selectively downregulate ISG synthesis in order to fine-tune the IFN response. Collectively, this differential network map of the IFN-induced interactome provides a resource to mechanistically dissect the IFN response in the context of viral infection and autoimmune disease. 


\section{Results}

\section{Proteome-wide analysis of the type I IFN response}

Whereas the transcriptional response to IFN stimulation has been extensively characterized, the dynamic changes occurring at the proteome level remain unclear. In view of the multiple biological mechanisms that exist to decouple protein abundance from mRNA expression [18], we therefore first sought to establish the proteome-wide response to IFN- $\beta$ (hereafter, "IFN") stimulation. We applied stable isotopic labeling by amino acids in cell culture (SILAC)-based mass spectrometry to precisely quantify protein abundance in HeLa cells after $4 \mathrm{~h}$ or $24 \mathrm{~h}$ of IFN stimulation (Fig. 1a). A total of 7421 proteins were identified, of which 5016 were quantified in all three replicates (Additional file 2). After $4 \mathrm{~h}$ of IFN stimulation, a timepoint by which most ISGs have reached their maximal mRNA expression [8], we detected 924 differentially expressed proteins at a 5\% FDR, but only 36 with greater than twofold induction (Fig. 1b). Conversely, after $24 \mathrm{~h}$ of IFN stimulation, we observed more pronounced changes in the cellular proteome, with 1172 proteins differentially expressed at 5\% FDR and 105 with at least a twofold induction (Fig. 1c, Additional file 1: Fig. S1A). Several proteins with well-appreciated roles in the type I IFN response were induced over 100-fold, including the IFIT proteins (IFIT1, IFIT2, and IFIT3), MX1, and ISG15 (Additional file 2).

Functional enrichment analysis of the proteins that were differentially expressed at $4 \mathrm{~h}$ or $24 \mathrm{~h}$, or which were differentially expressed between the two timepoints, revealed marked temporal differences in the cellular processes activated by IFN stimulation (Fig. 1d, e, Additional file 1: Fig. S1B, Additional file 3). Proteins that were differentially expressed at $4 \mathrm{~h}$ were enriched for Gene Ontology (GO) terms related to involvement in metabolic processes, such as "glycolipid catabolic process" and "regulation of steroid biosynthetic process," consistent with the notion that IFN signaling may induce changes to cellular metabolism in order to establish an antiviral state [20,21]. Other enriched GO terms pointed to a role for cell migration, including "regulation of macrophage migration" and "cell morphogenesis." In contrast, some of the most significantly enriched GO terms at $24 \mathrm{~h}$ were related to chromatin rearrangements: for instance, "DNA conformational change" and "DNAreplication-dependent nucleosome assembly." These enrichments are in line with the finding that IFN stimulation induces chromatin modifications to establish a transcriptional "memory," resulting in faster and greater transcriptional responses upon restimulation [22]. Enrichment was also observed for processes such as "posttranscriptional gene silencing," "gene silencing by RNA," and "de novo protein folding," which may reflect the changing cellular environment after IFN stimulation in preparation for host defense. Surprisingly, despite the rapid induction of ISG transcription (as early as $30 \mathrm{~min}$ post-stimulation [8];), we did not observe an enrichment of Gene Ontology (GO) terms related to the innate immune response until $24 \mathrm{~h}$, reflecting an apparent lag in translation of canonical ISGs (Fig. 1b, c).

Our attention was drawn to the enrichment for GO terms related to protein-protein interactions after $24 \mathrm{~h}$ of IFN stimulation, including "protein binding," "protein heterodimerization," and "protein heterotetramerization." We therefore sought to determine whether proteins that were differentially expressed at $24 \mathrm{~h}$, in comparison to cells stimulated with IFN for $4 \mathrm{~h}$ or to unstimulated cells, displayed a statistically significant tendency to physically interact. To test this hypothesis, we compared the observed number 


\section{A}

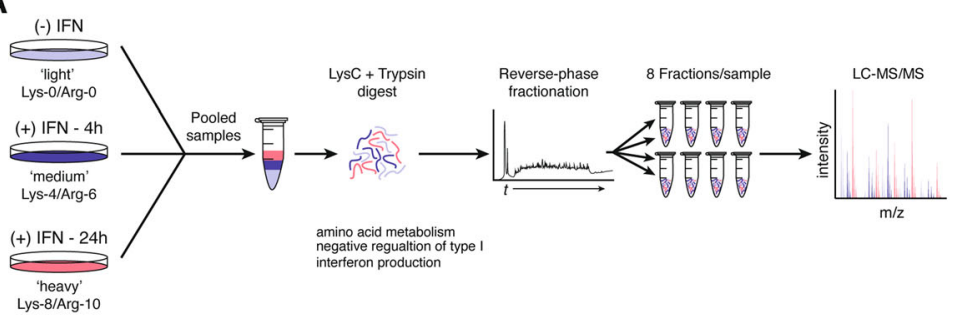

B

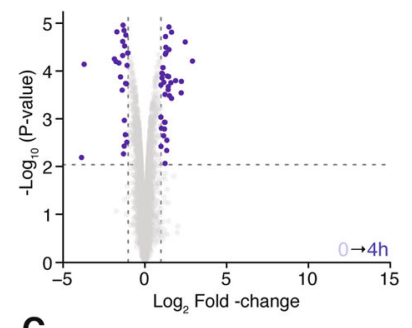

c

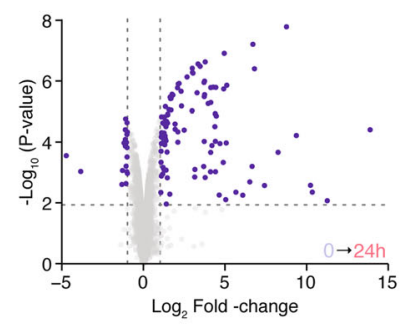

D go Biboosice Process

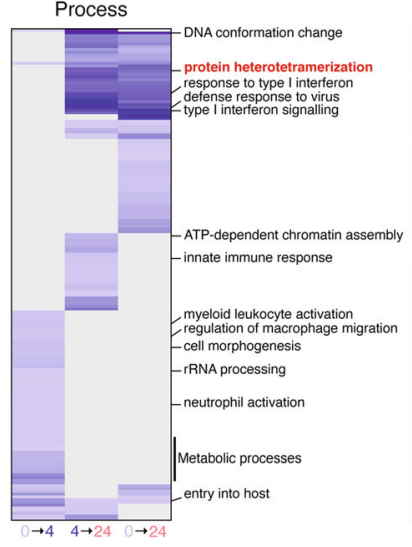

$-\log _{10}\left(P_{\text {acj }}\right) \frac{}{T_{1} \quad 5 \quad>10}$
E

GO Molecular Function

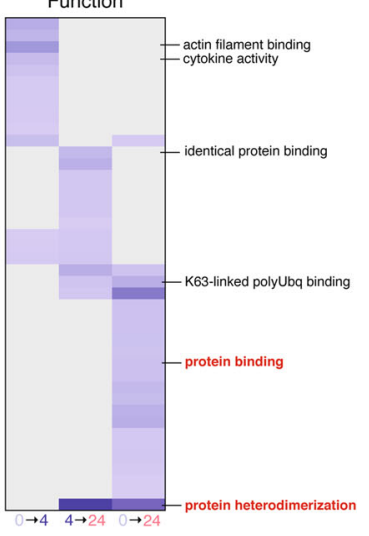

$-\log _{10}\left(P_{\text {adj }}\right) \frac{}{1 \quad 5}$

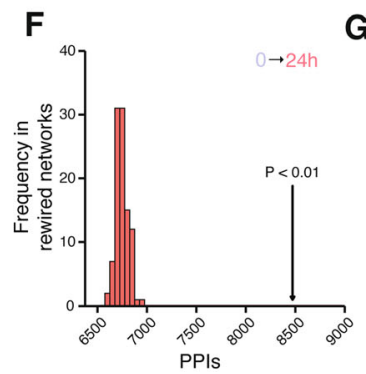

G
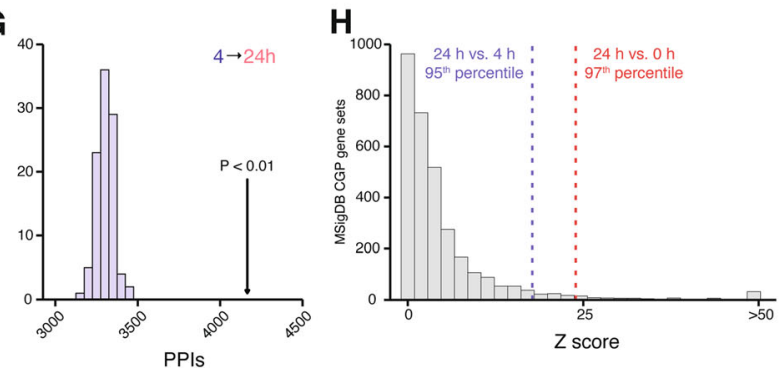

Fig. 1 Quantitative proteomic analysis of IFN $\beta$ stimulation. a Schematic overview of the shotgun proteomics workflow for analysis of IFN-induced proteome changes. $\mathbf{b}$, c Volcano plot showing differential protein abundance in cells stimulated with IFN $\beta$ for $4 \mathrm{~h}$ (b) or $24 \mathrm{~h}$ (c). Vertical lines denote absolute fold change $\geq 2$. Horizontal lines show 5\% FDR threshold. d, e Gene Ontology (GO) terms for biological processes (d) and molecular functions (e) significantly enriched among differentially expressed proteins after $4 \mathrm{~h}$ or $24 \mathrm{~h}$ of IFN $\beta$ stimulation. $\mathbf{f}, \mathbf{g}$ Number of protein-protein interactions in the InBioMap database [19] between differentially expressed proteins after $24 \mathrm{~h}$ (f) of IFN $\beta$ stimulation, or between cells stimulated for 4 and $24 \mathrm{~h}(\mathbf{f})$, arrows, and in 100 randomly rewired networks derived from the same database, histograms. $\mathbf{h}$ Enrichment for proteinprotein interactions between 3263 curated gene signatures from the MSigDB chemical and genetic perturbations collection, histogram, and the sets of proteins differentially expressed after $24 \mathrm{~h}$ of IFN stimulation relative to unstimulated cells or cells stimulated with IFN for $4 \mathrm{~h}$, dotted lines

of protein-protein interactions between differentially expressed proteins in each of the two comparisons, using the InBio Map database [19], to the number of interactions observed in networks rewired using degree-preserving randomization [23]. Importantly, unlike a null model in which an equivalent number of proteins are drawn at random from the network, this rewiring-based null model controls for artifactual differences stemming from the degree distribution of the network, whereby a statistically significant result can 
reflect the high connectivity of the differentially exposed proteins across the entire network as opposed to their selective interconnectivity with one another [24, 25]. This analysis revealed a substantial excess of physical protein-protein interactions between differentially expressed proteins, relative to random expectation (Fig. 1f, g). We compared the strength of this enrichment to that observed for 3263 curated gene expression signatures of disparate biological and clinical states cataloged in the MSigDB "chemical and genetic perturbations" (CGP) collection. Remarkably, proteins differentially expressed in the $24 \mathrm{~h}$ vs. $4 \mathrm{~h}$ and $24 \mathrm{~h}$ vs. unstimulated comparisons displayed a greater enrichment for physical interactions than $95 \%$ and $97 \%$ of CGP signatures, respectively (Fig. 1h). Together, these results led us to hypothesize that in addition to its effects on ISG transcription, IFN stimulation induces rewiring of cellular protein-protein interaction networks.

\section{Quantitative interactome profiling of the type I IFN response}

To map rearrangements in the human interactome induced by IFN stimulation, we applied a quantitative proteomic strategy based on protein correlation profiling (PCP) $[26$, 27] in combination with size exclusion chromatography (SEC). Under this workflow, protein complexes are separated by their size, and interacting protein pairs are inferred based on the similarity of their elution profiles (Fig. 2a). The use of triplex SILAC labeling (SECPCP-SILAC) further enables differential analysis of protein-protein interactions between stimulated and unstimulated cellular states, to a high degree of quantitative precision [17].

We applied SEC-PCP-SILAC to simultaneously compare the interactomes of cells stimulated with IFN for $24 \mathrm{~h}$, labeled with heavy isotopes, and unstimulated cells, labeled with medium isotopes (Fig. 2a). Fractions from the light channel, which included both stimulated and unstimulated cells in order to maximize proteome coverage, were pooled and spiked into all fractions as an internal standard. Sixty fractions were collected from each of three biological replicates and were individually subjected to liquid chromatographytandem mass spectrometry (LC-MS/MS) analysis. The resulting dataset was processed as a single experiment via MaxQuant [29] at a peptide and protein false discovery rate (FDR) of $1 \%$, leading to the identification of 42,843 unique peptides from 2590 protein groups across all 180 fractions (Fig. 2d). Inspection of the PCP chromatograms revealed marked shifts between conditions for protein complexes with known roles in the innate immune response, such as the immunoproteasome (Fig. 2b). Conversely, no differences between conditions were observed for housekeeping complexes such as the mitochondrial $F_{1} F_{0}-$ ATP synthase, supporting the specificity of the technique (Fig. 2c).

\section{Reconstruction of a high-confidence interactome network}

To recover a high-confidence network of protein-protein interactions, we developed a multi-stage bioinformatic pipeline. First, whereas discussion of error rates in quantitative proteomics to date has focused primarily on errors in protein identification [30, 31], we observed a number of apparent errors in protein quantitation, some of which resulted in high-magnitude deviations in protein chromatograms (Additional file 1: Fig. $\mathrm{S} 2 \mathrm{C})$. Errors of this type have the potential to interfere with interaction detection or to introduce spurious differential interactions between conditions. We therefore developed a network-based algorithm, MODERN, to remove erroneous protein quantitations prior to further analysis (see the "Methods" section). Application of MODERN to all three 


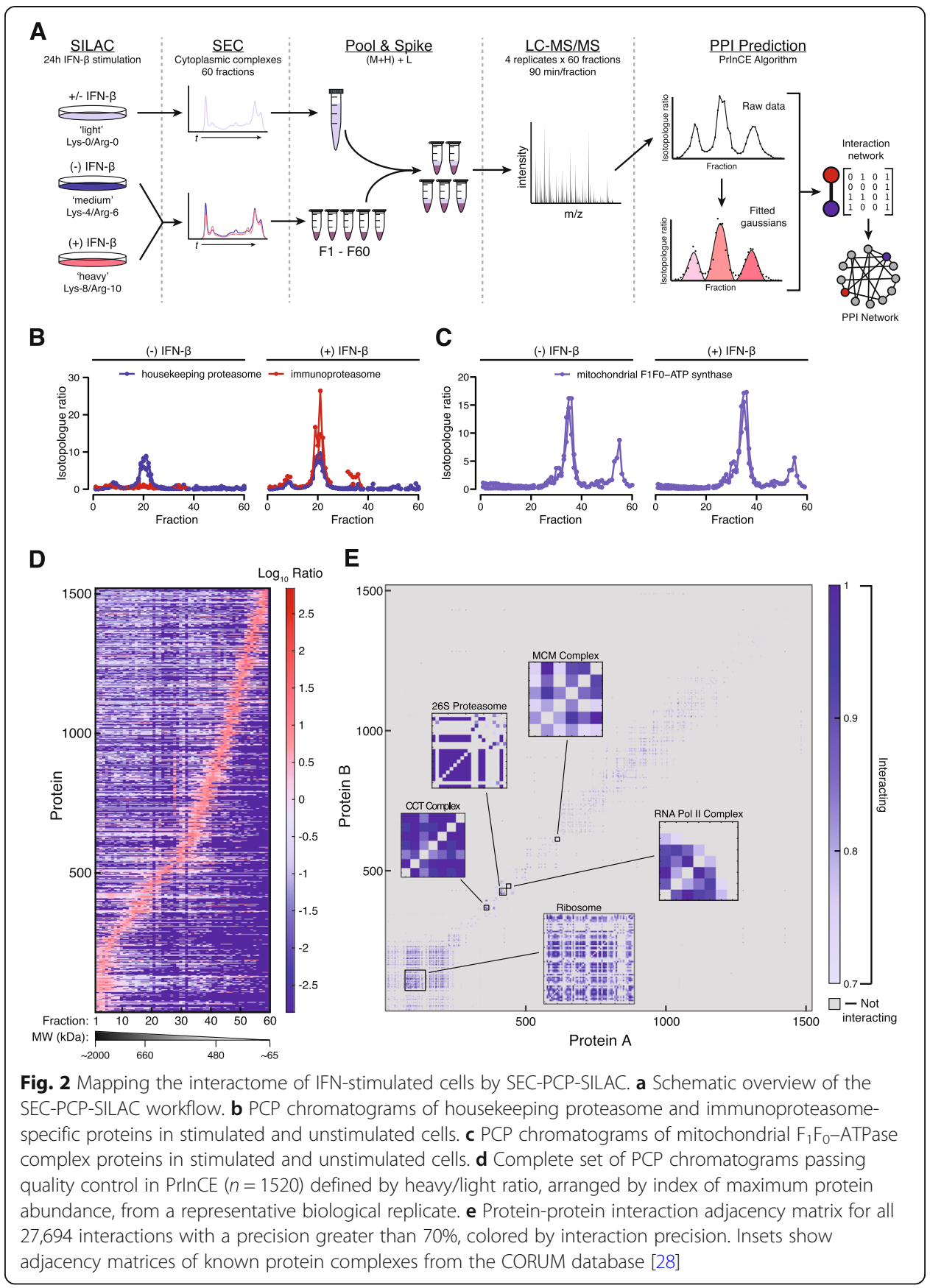

replicates led to removal of 1308 erroneous protein quantitations (of 245,841 total quantitations, or 0.53\%; Additional file 1: Figs. S2A-B).

Next, to infer a network of protein-protein interactions from the resulting chromatogram matrices, we applied PrInCE, a machine-learning pipeline for analysis of co-fractionation data [32, 33]. PrInCE fits a mixture of Gaussians to each chromatogram, then calculates a series of six features for each protein pair that reflect the likelihood of a physical interaction between those two proteins (see the "Methods" section). These features are provided as input to a naive Bayes classifier, which calculates an interaction probability for every pair. Importantly, PrInCE assigns the likelihood of putative interactions based solely on the 
chromatograms themselves, without incorporating additional evidence from published functional genomics datasets, in contrast to several other approaches [34-37]. This approach facilitates unbiased detection of novel protein-protein interactions, without sacrificing discriminative power [38].

At a precision of $70 \%$, PrInCE recovered a total of 26,361 protein-protein interactions involving 1049 proteins (Fig. 3a, Additional file 4). Visualization of the adjacency matrix revealed a sparse network of physical interactions and confirmed recovery of well-known cellular protein complexes, such as the $26 \mathrm{~S}$ proteasome, the chaperonin containing TCP-1 complex, and RNA polymerase II (Fig. 2e). To more systematically assess the recovery of known protein complexes, we compared the network to the CORUM database, finding 206 of 296 human protein complexes (69.6\%) had at least one subunit represented in the network (Additional file 1: Fig. S3A and C, Additional file 5). This proportion rose to $81.4 \%$ (96 of 118) when considering only those complexes previously found to be amenable to detection by PCP [40] (Additional file 1: Fig. S3B and D), and was broadly similar for protein complexes of different sizes (Additional file 1: Fig. S3E-F), albeit with a modest bias towards large complexes. Among the 16,927 unique interactions detected in either condition, 4046 represented co-complex interactions within known CORUM protein complexes, corresponding to a recall of $6.9 \%$ of unique interactions in CORUM and $15.0 \%$ within the subset of complexes amenable to detection by PCP (Additional file 1: Fig. S3G).

Among the 26,361 protein-protein interactions detected overall, 11,924 were identified in unstimulated cells and 14,437 in IFN-stimulated cells, with 9434 detected under both conditions (Fig. 3c-d and Additional file 1: Fig. S4A-B). Thus, $71.6 \%$ of all detected interactions were identified in both networks. This rewiring could not be attributed solely to the variable protein composition of the two networks, as a smaller proportion of protein nodes themselves were specific to one of the two networks (Fig. 3d). To investigate the degree to which changes in protein abundance in response to IFN stimulation could underlie the observed rewiring, we overlaid our shotgun proteomics data (at the 24-h timepoint; Fig. 1c) onto the IFN-stimulated and unstimulated networks (Additional file 1: Fig. S4C-D, Additional file 4). A total of 6562 unique interactions involved at least one protein with a statistically significant difference in abundance upon IFN stimulation, but most of these proteins exhibited relatively subtle changes in expression (Fig. 3e). In contrast, fewer interactions involved proteins with more dramatic IFNinduced changes in abundance (i.e., twofold or greater). Moreover, whereas interactions involving differentially expressed proteins were equally likely to be observed in either or both of the IFN-stimulated or unstimulated networks ( $p=0.20, \chi^{2}$ test), interactions involving proteins with twofold or greater differences in abundance were significantly enriched among the set of condition-specific interactions $\left(p<10^{-15}, \chi^{2}\right.$ test; Additional file 1: Fig. S4E). To further assess this trend, we calculated, for all interactions, the maximum $\log _{2}$-fold change within the interacting protein pair and confirmed that only a small fraction of interactions involve proteins with dramatic changes in abundance (Fig. 3f, Additional file 1: Fig. S4F).

Overall, these results suggest that only a small number of condition-specific interactions involve proteins with pronounced IFN-induced changes in abundance. More subtle changes in expression affect a larger number of interactions and might act to "finetune" interactions. However, the large number of interactions between proteins that are not differentially expressed in response to IFN stimulation suggests a role for other 


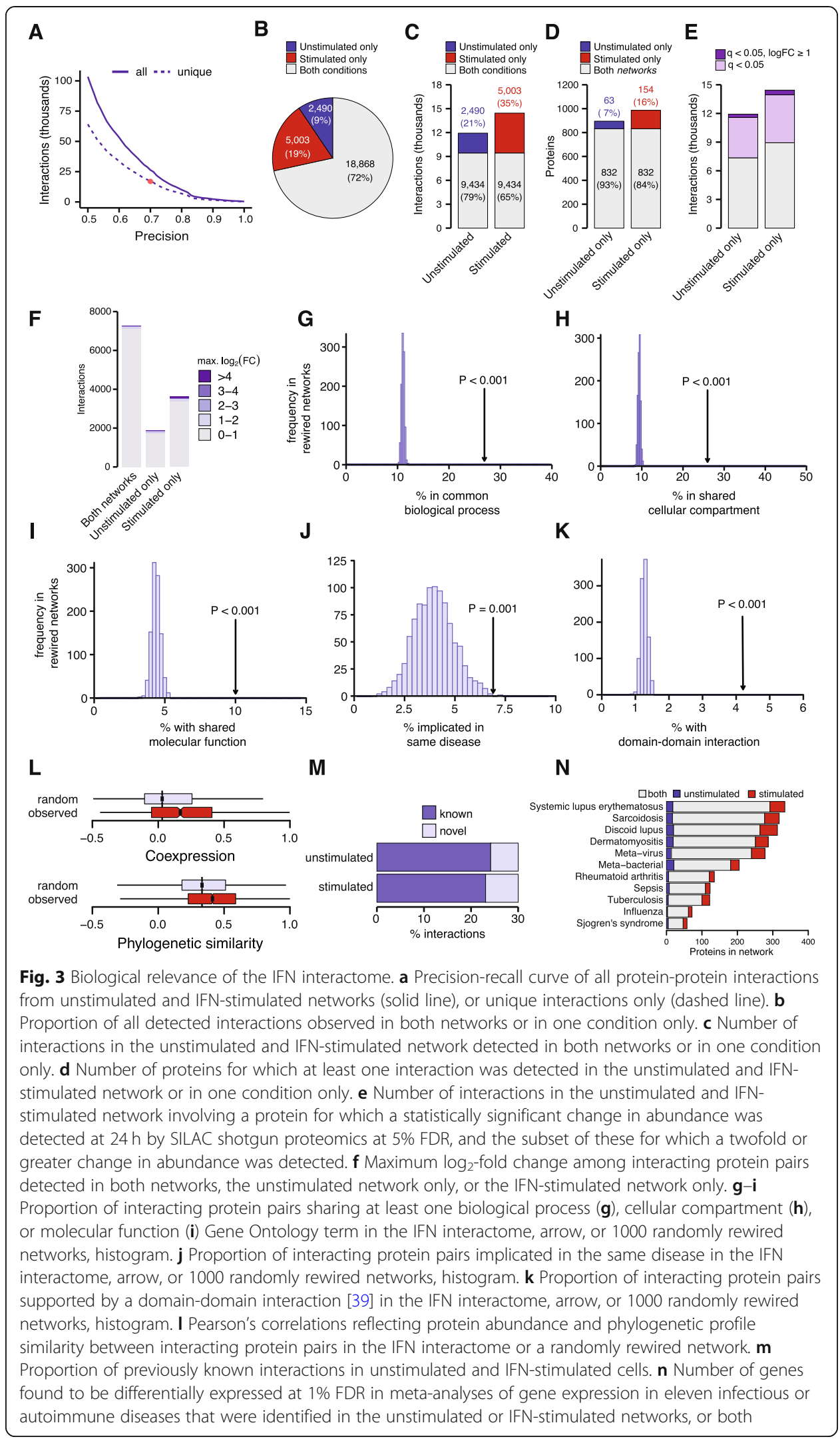


mechanisms, such as post-translational modification, subcellular localization, or protein degradation, in IFN-dependent interactome remodeling.

\section{Biological relevance of the IFN interactome}

We evaluated the overall biological relevance of the IFN-induced interactome by quantifying the degree to which interacting protein pairs tend to be involved in the same biological functions, localize to the same cellular compartments, or share the same molecular activities (Fig. 3g-i). In all cases, we observed highly significant enrichments for shared GO terms between interacting pairs, relative to rewired networks (all $p<0.001$, permutation test). Further, we found interacting protein pairs were significantly more likely than random expectation to be implicated in the same disease $(p=0.005$, permutation test; Fig. 3j), and had more correlated patterns of protein abundance and phylogenetic profiles than non-interacting pairs $\left(p<10^{-15}\right.$, Brunner-Munzel test; Fig. 3l). Finally, interacting proteins were significantly more likely to share pairs of protein domains observed to physically interact in three-dimensional structural data [39], reflecting the power of SEC-PCP-SILAC to resolve physical protein-protein interactions, and not only functional associations $(p<0.001$, permutation test; Fig. 3k). The enrichment for known correlates of physical interaction observed in the SEC-PCP-SILAC network was broadly comparable to, although slightly lower than, literature-curated interactions from smallscale experiments compiled in the InnateDB database (Additional file 1: Fig. S5A-G) [41]. Despite this enrichment, however, comparison of the IFN interactome to literaturecurated protein-protein interactions recorded in eighteen databases revealed that the majority of interactions $(13,240$ of 16,927 , or $78.2 \%)$ detected were novel. Intriguingly, the IFN-stimulated network was modestly depleted for known interactions, relative to the unstimulated network ( $p=0.042, \chi^{2}$ test; Fig. $3 \mathrm{~m}$ ), suggesting IFN stimulation specifically induces as-of-yet unmapped protein-protein interactions. Thus, multiple orthogonal lines of evidence support the high quality of our IFN interactome map, despite its recovery independent of any existing biological information.

Given that aberrant IFN signaling has been implicated in a broad range of infectious or autoimmune diseases, we further asked whether the IFN interactome could be used to interpret existing molecular datasets relevant to human pathologies. We drew on a resource of multi-cohort gene expression meta-analyses for 103 diseases [42, 43] to identify genes with reproducible evidence of differential expression in eleven diseases characterized by an elevated IFN transcriptional signature [8], including viral infections, systemic and discoid lupus erythematosus, rheumatoid arthritis, sarcoidosis, and Sjogren's syndrome. We mapped protein-protein interactions for dozens to hundreds of differentially expressed genes from each disease (Fig. 3n); notably, interactions for many such gene products were identified exclusively in the IFN-stimulated condition. For ten of eleven diseases, genes upregulated at a 1\% FDR were significantly over-represented among interactions detected only after IFN stimulation (Additional file 1: Fig. S5H). Moreover, for all eleven diseases, these genes were significantly enriched among IFN-specific interactions compared to literature-curated interactions compiled from eighteen databases (Additional file 1 : Fig. $\mathrm{S} 5 \mathrm{H})$. Thus, the IFN interactome provides a reference to understand the consequences of dysregulated IFN signaling in a diverse range of human pathologies, by placing transcriptional markers of auto-inflammatory disease into a functional context. 


\section{Evolutionary plasticity of the IFN response is mirrored at the interactome level}

Comparative genomics approaches have highlighted genes involved in pathogen defense and the innate immune response as rapidly evolving, with divergence in both coding and regulatory sequences across species [44-46]. However, it remains unclear how this evolutionary divergence at the sequence level ultimately manifests at the interactome level. We quantified the degree to which each protein is "rewired" upon IFN stimulation within the human interactome by calculating its autocorrelation between stimulated and unstimulated networks [47] (see the "Methods" section). The tier of proteins with the lowest autocorrelation scores included several proteins with well-established roles in the innate immune response, such as the IFIT proteins and components of the immunoproteasome (Additional file 1: Fig. S6A, Additional file 6). Comparing the IFN-induced autocorrelation of each protein to its evolutionary rate, as quantified by the ratio of non-synonymous to synonymous substitutions $(\mathrm{dN} / \mathrm{dS})$, revealed a modest, but statistically significant negative correlation (Spearman's $\rho=-0.11, p=1.9 \times 10^{-4}$; Additional file 1: Fig. S6B). Similarly modest but significant associations were observed in comparisons to the total number of species in which an ortholog of a given gene was present $\left(\rho=0.14, p=5.3 \times 10^{-7}\right.$; Additional file 1: Fig. $\mathrm{S6C)}$ [48], or to the pLI score [49], a measure of mutational constraint derived from largescale human exome sequencing $\left(\rho=0.18, p=5.9 \times 10^{-5}\right.$; Fig. S6D). Moreover, these associations remained consistent when controlling for changes in protein abundance observed in the shotgun proteomics data using the partial Spearman correlation $\left(p \leq 2.6 \times 10^{-4}\right)$, when analyzing the data using linear regression $\left(p \leq 6.2 \times 10^{-3}\right.$; Fig. S6E), and when sampling with replacement from the underlying SEC-PCP-SILAC chromatograms (Fig. S6B-D). Collectively, these results indicate that rapidly evolving proteins are disproportionately rewired in the protein-protein interaction network by IFN signaling, to a degree that cannot be explained by changes in protein abundance alone, suggesting that species-specific differences in the innate immune response may be mediated in part through the effects of protein sequence divergence on protein-protein interactions.

\section{Functional landscape of IFN signaling}

Despite the high quality of our IFN interactome, high-throughput maps of protein-protein interactions are unavoidably characterized by both false positives and false negatives [50]. We therefore sought to characterize the impact of IFN signaling on the human proteinprotein interaction network more broadly, by developing a statistical framework for differential network analysis at the functional level (Additional file 1: Fig. S7A). Briefly, our approach first calculates the number, $n_{P P I}$, of protein-protein interactions in both the stimulated and unstimulated networks involving proteins associated with a functional category of interest, and the difference between them, $\Delta n_{P P I}$. To assess statistical significance, the observed $\Delta n_{P P I}$ is compared to a randomized distribution obtained from the $n_{P P I}$ values of 1000 randomly rewired networks. The network rewiring procedure controls for biases stemming from network topology that may be independent of functionally relevant patterns [23, 24, 51].

A total of 341 GO terms were significantly enriched in either stimulated or unstimulated networks at 20\% FDR and were visualized as an enrichment map [52] (Fig. 4b, Additional file 7). As expected, we observed a significant enrichment for interactions between proteins involved in the innate immune response in the IFN-stimulated network, including GO terms such as "antigen processing and presentation" (Fig. 4, 
Additional file 1: Fig. S7B). The Wnt signaling pathway was likewise enriched in the IFN-stimulated network, consistent with its link to type I IFN signaling [53, 54] (Additional file 1: Fig. S7B). Intriguingly, the stimulated network was also enriched for terms relating to RNA processing and splicing, suggesting a role for physical interactions in the regulation of alternative splicing during the host response to viral infection $[1,55]$. Conversely, the stimulated network was depleted for interactions involving chromatin remodeling and histone-modifying machinery, as well as interactions involved in negative regulation of ubiquitination. Surprisingly, we observed a significant enrichment for interactions related to translation and ribosome biogenesis upon IFN stimulation (Fig. 4, Additional file 1: Fig. S7B), potentially accounting for the apparent lag observed in our shotgun proteomics experiment between ISG transcription and translation. To test whether these enrichments specifically reflected IFN-induced changes in interactome structure, as opposed to differences in the protein content of the stimulated and unstimulated networks, we performed a separate functional enrichment analysis of the proteins found in either network, but found little overlap between GO terms identified as enriched by interaction rewiring-based and protein content-based methods (Additional file 1: Fig. S7C). Collectively, these observations reflect wide-ranging functional changes within the human interactome induced by IFN signaling.

\section{Interactions between evolutionarily conserved ISGs modulate the type I IFN response}

Large-scale transcriptomic studies of the innate immune response across species and cell types have contrasted extensive heterogeneity in species- or cell type-specific transcriptional programs with a core module of universally upregulated genes, anchoring the transcriptional response across evolutionary and cellular contexts [7-9]. We sought to characterize the properties of evolutionarily conserved and species-specific ISGs at the interactome level. Using data from a comparative transcriptomic study of ten vertebrates [7], we defined sets of genes upregulated by IFN in all species ("core ISGs"), in human and at least one other species ("conserved ISGs"), or in humans only ("human-specific ISGs"). We then asked whether our SEC-PCP-SILAC data supported the hypothesis that ISGs in each category are induced to interact physically with one another in response to IFN stimulation. To address this hypothesis, we calculated the correlation between all pairs of ISGs in each condition and tested for a significant increase in the median correlation. Strikingly, only the core set of evolutionarily conserved ISGs displayed a significant shift in chromatogram correlation upon IFN stimulation $\left(p=6.9 \times 10^{-3}\right.$, Brunner-Munzel test; Fig. 5a), suggesting these ISGs enter physical interactions or protein complexes during the IFN response, at least within HeLa cells. Similar results were obtained when using the approach described in Additional file 1: Fig. S7A to test for network rewiring, with significantly more interactions between core ISGs in the IFN-stimulated network ( $p=$ $0.0072)$, but not conserved or human-specific ISGs $(p \geq 0.36)$. As expected, despite their evolutionarily conserved induction in response to IFN stimulation, these core ISGs are also rapidly evolving at the protein sequence level, consistent with the data presented in Additional file 1: Fig. S3 ( $p=2.0 \times 10^{-8}$, Brunner-Munzel test; Additional file 1: Fig. S8A).

To experimentally validate this observation, we performed co-immunoprecipitations of four core ISGs in unstimulated or IFN-stimulated cells (Fig. 5b, Additional file 8). In three of four co-immunoprecipitations, core ISGs were significantly and selectively 


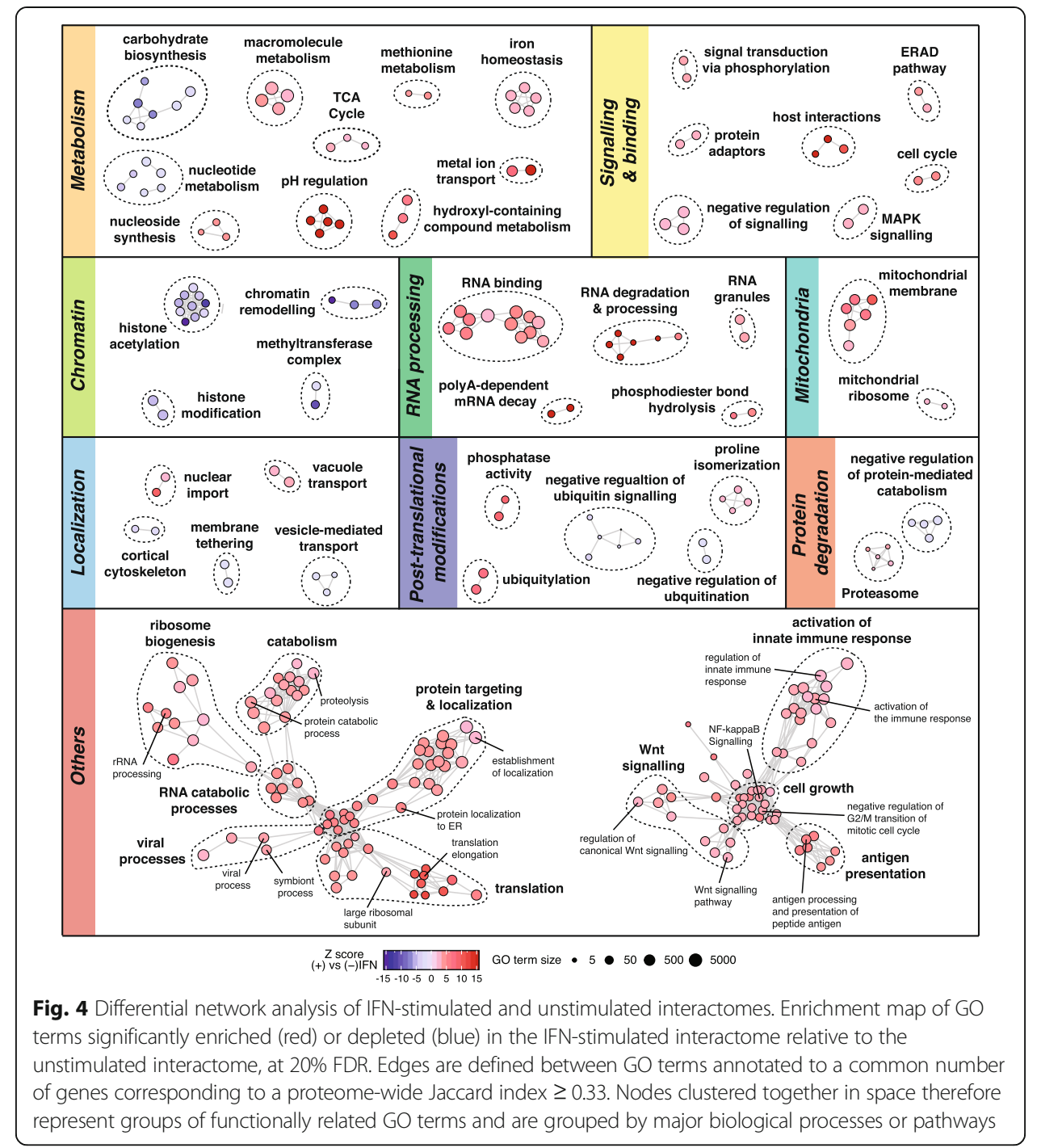

enriched among interactors after IFN stimulation, relative to conserved or humanspecific ISGs (gene set enrichment analysis, $p \leq 5.1 \times 10^{-3}$; Fig. $5 \mathrm{c}$ ). Moreover, this enrichment was robust to filtering potential non-specific interactors from the CRAPome database (Additional file 1: Fig. S8B) [57].

To shed light on the functional consequences of physical interactions between core ISGs, we focused on the interaction between IFI35 and STAT1, which was detected in IFNstimulated cells by both SEC-PCP-SILAC (Fig. 5d, Additional file 4) and coimmunoprecipitation of STAT1 (Additional file 1: Fig. S8C). Notably, we could not recover STAT1 in immunoprecipitations of IFI35, although we could recover its known binding partner NMI $[58,59]$. Immunoprecipitations of NMI, which has previously been shown to interact with STAT1 during IFNY treatment [60], likewise recovered IFI35, but did not reproducibly recover STAT1 (Additional file 1: Fig. S8C). These observations suggest that the interaction between STAT1 and IFI35 may be substoichiometric, whereby not all cellular IFI35 is bound to STAT1, or may potentially occur in an IFN $\beta$-specific manner. Furthermore, the interaction of IFI35 and STAT1 was also detected in a monocyte-derived cell line, 


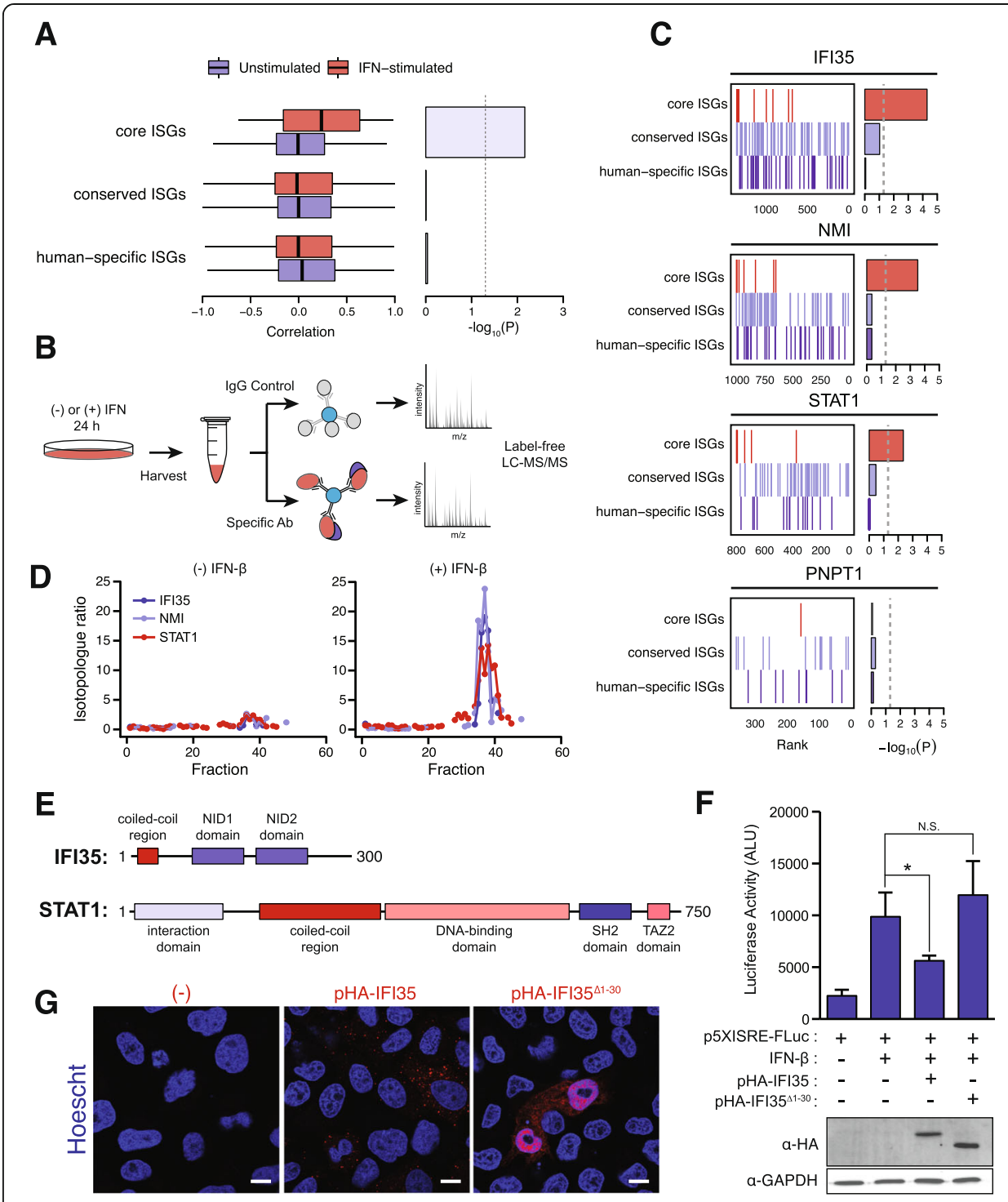

Fig. 5 Interactions between evolutionarily conserved ISGs modulate the transcriptional response to IFN stimulation. a Left, distribution of correlations between pairs of proteins from core, conserved, and humanspecific ISG sets in PCP chromatograms. Right, negative base-10 logarithm of $p$ values from Brunner-Munzel tests of the difference in medians. $\mathbf{b}$ Schematic overview of the affinity purification-mass spectrometry experiments of specific core ISGs in IFN-stimulated or unstimulated cells. c Gene set enrichment analysis barcode plots [56], showing ranks of core, conserved, and human-specific ISG products in comparisons of immunoprecipitations of IFI35 (left), NMI (middle), and STAT1 (right) from IFN-stimulated or unstimulated cells, alongside negative base-10 logarithms of $p$ values for each ISG set. $\mathbf{d}$ PCP chromatograms from a representative replicate of IFI35, NMI, and STAT1 in IFN-stimulated and unstimulated cells. e Protein domain content of IFI35 (top) and STAT1 (bottom). f Top, luciferase activities from cells transfected with a $5 \times$ ISREFluc reporter construct to monitor STAT1 transcriptional activity $( \pm S D)$. Cells were transfected with equal amounts of DNA in each case. Bottom, western blots of HA-tagged IFI35 expression from lysates transfected with reporter constructs. ${ }^{*} p<0.05$. g Immunofluorescence micrographs of cells mock transfected or transfected with HA-tagged IFI35 expression constructs. Shown is a representative image. Scale bar $=10 \mu \mathrm{m}$

THP-1 (Additional file 1: Fig. S8D), suggesting that this interaction is not limited to HeLa cells.

Given the role of IFI35 in repression of the IFN response through other mechanisms such as promoting degradation of RIG-I and decreasing IFN $\beta$ production $[61,62]$, we 
hypothesized that the interaction between IFI35 and STAT1 functioned to reduce STAT1 transcriptional activity as a potential mechanism to downregulate the IFN response. To investigate this hypothesis experimentally, we made use of a reporter construct containing $5 \times$ Interferon-Sensitive Response Elements (ISREs) fused to a firefly luciferase gene to monitor STAT1 transcriptional activity. Cells were transfected with the reporter construct, followed by transfection with a construct overexpressing hemagglutinin (HA)tagged IFI35 and subsequent IFN stimulation. Control cells displayed low levels of luciferase activity that increased substantially upon IFN stimulation, as expected (Fig. 5f). Expression of an N-terminal HA-tagged IFI35 resulted in a significant decrease in luciferase activity, suggesting that STAT1 transcription is impaired (Fig. 5f). To further understand the mechanism underlying STAT1 transcriptional repression, we hypothesized that the IFI35-STAT1 interaction may be mediated by the $\mathrm{N}$-terminal coiled-coil domain of IFI35, with the internal coiled-coil domain of STAT1 its potential interaction partner (Fig. 5e). Consistent with this hypothesis, truncation of the coiled-coil domain from IFI35 recovered luciferase activity in transfected cells, despite expression of the truncated protein at similar levels as the full length (Fig. 5f). Of note, unlike previous work on RIG-I, [61], we did not observe a decrease in STAT1 protein levels upon overexpression of IFI35, suggesting substantial degradation is likely not occurring (Additional file 1: Fig. S8E). To determine if truncating the coiled-coil region perturbs IFI35 function, we examined the localization of wild-type HA-IFI35 or its truncated form upon IFN stimulation. Immunofluorescent staining revealed that wild-type HA-IFI35 formed punctate cytoplasmic granules with IFN stimulation, as previously observed (Fig. 5g) [63, 64]. Strikingly, truncation of the first $30 \mathrm{~N}$-terminal amino acid residues of IFI35 dramatically shifted the localization, to diffuse cytoplasmic and nuclear staining (Fig. 5g). This data suggests that disruption of the IFI35 N-terminal region may alleviate inhibition of STAT1 activity by redistributing IFI35 localization in the cytoplasm.

Taken together, these data support a model whereby IFI35 interacts with STAT1, sequestering it to cytoplasmic granules to fine-tune STAT-1-mediated transcription in response to IFN stimulation.

\section{Ribosomal incorporation of RPL28 buffers ISG protein synthesis}

Motivated by the observation of significant enrichment for interactions involved in translation and ribosome biogenesis in the IFN-stimulated interactome (Fig. 4, Additional file 1: Fig. S7B), we investigated the relationship between the mRNA and protein levels of ISGs in greater detail. Examining the expression of ISGs at the mRNA level in a densely sampled time-course transcriptomic experiment [8], we found proteins that were differentially expressed after $4 \mathrm{~h}$ of IFN stimulation reached peak transcriptional levels between 0.5 and $3.5 \mathrm{~h}$ (Additional file 1: Fig. S8A). Surprisingly, however, a large proportion of proteins differentially expressed at $24 \mathrm{~h}$ had peak mRNA expression at similar timepoints (Additional file 1: Fig. S8B), suggesting a lag in their translation. Based on these observations, we hypothesized that a specialized translational program, potentially mediated by changes in ribosome composition [65], may be involved in establishing the IFN response.

To address this hypothesis, we performed sucrose density gradients to isolate free (40S, 60S, and 80S) and actively translating ribosomes (polysomes) in IFN-stimulated or unstimulated cells (Fig. 6a). Polysome traces revealed an increase in free ribosomes 


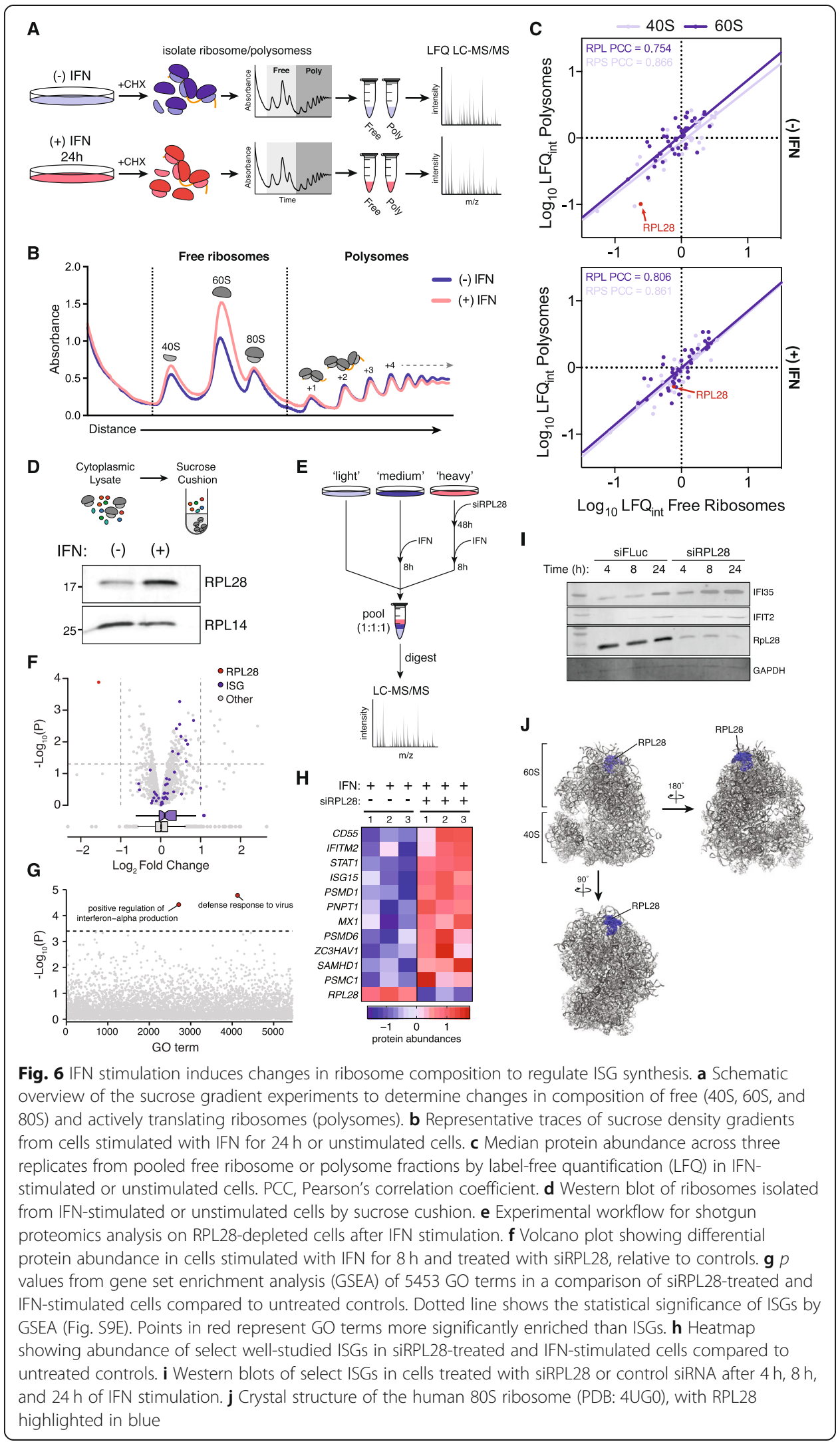


upon IFN stimulation, apparent from the heightened $40 \mathrm{~S}$ and $60 \mathrm{~S}$ peaks, but no detectable changes in polysome levels (Fig. 6b). To investigate changes in ribosome composition, fractions containing free ribosomes and polysomes, respectively, were pooled and subjected to quantitative mass spectrometry. Most ribosomal proteins were incorporated at similar levels in IFN-stimulated and unstimulated samples (Fig. 6c, Additional file 9). However, we observed a substantial and selective increase in RPL28 incorporation upon IFN stimulation (Fig. 6c). We confirmed this observation by western blots of isolated ribosomes from IFN-stimulated or unstimulated cells. A substantial increase in RPL28 was observed compared to a control ribosomal protein, RPL14, suggesting RPL28 is selectively incorporated into ribosomes during the IFN response (Fig. 6d).

We next sought to characterize the functional consequences of RPL28 incorporation during the IFN response. Over the past decade, it has become clear that ribosomes may not exist as a single homogenous population, but instead undergo dynamic changes in composition, with incorporation of individual ribosomal components forming "specialized ribosomes" that promote the translation of specific mRNA classes [66-69]. Based on this body of evidence, and the fact that RPL28 lies in a solvent-accessible portion of the ribosome (Fig. 6j), we hypothesized that IFN-dependent RPL28 incorporation facilitates translation of mRNAs related to the type I IFN response. In support of this hypothesis, examination of the Human Protein Atlas [70] and FANTOM5 database [71] indicated RPL28 is expressed at the highest levels in human immune system tissues, such as the thymus and lymph nodes (Additional file 1: Fig. S8C-D), consistent with a potential immunological role.

To determine the functional role of RPL28, we used siRNAs to knockdown RPL28 followed in the context of IFN stimulation to precisely quantify changes in protein synthesis. Cells labeled with heavy isotopes were treated with siRPL28 for $48 \mathrm{~h}$, after which both medium- and heavy-labeled cells were exposed to IFN for $8 \mathrm{~h}$, with unstimulated lightlabeled cells serving as a baseline control (Fig. 6e). A total of 1940 proteins were identified, of which 1421 were quantified in at least two of three replicates (Additional file 10). To our surprise, comparison of siRPL28-treated cells to controls revealed an increase in ISG abundance upon RPL28 knockdown (Fig. 6f, h), an effect which was highly significant by gene set enrichment analysis $\left(p=2.9 \times 10^{-4}\right.$; Fig. $\left.6 \mathrm{~g}\right)$. An unbiased enrichment analysis of the RPL28 knockdown data identified only two GO terms with a more statistically significant effect (Fig. 6g, Additional file 11), both of which ("positive regulation of interferonalpha production" and "defense response to virus") overlapped substantially with proteins having known roles in the IFN response. We further confirmed this finding by western blot, observing increases in ISG abundance over time in the RPL28 knockdown compared to an siRNA control (Fig. 6i). Importantly, to rule out the possibility that RPL28 leads to impaired ribosome biogenesis and global downregulation of translation rates [72], we monitored protein synthesis by metabolic labeling with $\left[{ }^{35} \mathrm{~S}\right]$-Met/Cys, finding that RPL28 depletion did not alter global protein levels in either our SILAC experiment (Fig. 6f) or when assessed with metabolic labeling (Additional file 1: Fig. S9E), suggesting that the ribosome remains functionally competent.

We next asked whether this phenomenon is specifically associated with knockdown of RPL28,or whether it occurs in response to perturbation of ribosomal proteins more generally. To this end, we compared the proteome of IFN-stimulated cells after treatment with 
siRNAs targeting RPL28, RPS26, or RPS28 using label-free quantitation (Additional file 12). Following RPL28 knockdown, we reproduced the results from our first experiment, observing a significant increase in ISG abundance upon RPL28 depletion $\left(p=7.1 \times 10^{-4}\right.$; Additional file 1: Fig. S10A). However, this effect was not observed after depletion of RPS26 or RPS28 ( $p=0.69$ and 0.18 , respectively; Additional file 1: Fig. S10B-C), indicating that the increase in ISG abundance is specific to perturbation of RPL28.

Finally, it is possible that the changes observed in ISG abundance are merely due to an increase in mRNA levels. To further rule out the possibility that the changes in ISG protein abundance are mediated primarily by an increase in mRNA levels, we performed RT-qPCR, which did not reveal a significant difference between siRPL28- or control-treated cells (with the exception of NMI; Additional file 1: Fig. S9F). Taken together, these results suggest that RPL28 is specifically incorporated into ribosomes upon IFN stimulation, where it acts to selectively downregulate ISG protein synthesis.

\section{Discussion}

The pleiotropic effects of type I IFN stimulation on transcriptional regulation have been appreciated for over two decades [2]. In turn, the maturation of increasingly sensitive technologies for transcriptome profiling, complemented by functional assays, has led to the identification of hundreds of ISGs [6]. Yet, with relatively few exceptions, the functional roles of these effectors in the antiviral response remain incompletely delineated. In particular, little is known about how existing cellular networks are influenced by IFN stimulation and how newly synthesized ISGs engage these complex networks.

Here, we have used protein correlation profiling to construct a differential network map of the human protein-protein interactome in response to type I IFN signaling. This map identifies specific interactions for known ISGs under homeostatic conditions and reveals patterns of interaction rewiring induced by IFN stimulation. The IFN interactome thus places ISGs into a functional context, providing a platform for further mechanistic dissection of their roles in the innate immune response. For example, we find that IFI35 binds to STAT1 to potentially fine-tune its transcriptional activity, further defining the role of IFI35 as a direct negative regulator of the IFN response. Given the dysregulation of IFN signaling in both monogenic diseases [5], as well as a broader spectrum of autoimmune and neuropsychiatric disorders [4], our work provides a framework to develop a deeper understanding of the mechanisms that protect against inappropriate immune activation.

Our functional analysis of the IFN-induced differential interactome implicated rewiring of interactions involved in protein translation and ribosome biogenesis in the IFN signaling cascade, leading us to uncover a novel regulatory mechanism involved in the innate immune response. We find that increased incorporation of RPL28 into the ribosome upon IFN stimulation represses synthesis of ISGs, whereas global translation remains unaffected. This effect was not observed when we perturbed other components of the ribosome, suggesting specificity to RPL28. Given the need for tight regulation of the IFN response to avoid aberrant overactivation, RPL28 may act as a buffer on excessive ISG translation, in effect imposing a secondary layer of regulation beyond mRNA transcription. Overall, this finding adds to a growing body of literature demonstrating how modulation of ribosome composition may facilitate translational control of specific mRNA classes [67-69]. 
After $24 \mathrm{~h}$ of IFN stimulation, we observed dynamic rearrangements of the cellular protein-protein interaction network, affecting a broad spectrum of cellular pathways. At this relatively late timepoint, the observed interactome rewiring likely reflects not only the direct effects of IFN signaling, but also the downstream effects of IFN stimulation on cellular processes such as chromatin remodeling and metabolism, as observed in our shotgun proteomics dataset (Fig. 1). These changes in protein abundance and network connectivity may reflect the establishment of an antiviral state in uninfected "bystander" cells exposed to circulating IFN, similar to that observed during viral infections [73-75].

Our differential network map utilized HeLa cells to delineate the impact of IFN stimulation on the human interactome. HeLa cells have been widely used as a model to understand viral infections and the immune response, and express core type I IFN pathway components common to most cell types, including the ubiquitously expressed type I IFN- $\alpha / \beta$ receptor (IFNAR) [76] and downstream signaling components, such as JAK1, STAT proteins, and IRF9. Our experimental validation of the IFN-dependent interaction between STAT1 and IFI35 in a second cell type, the monocyte-derived cell line THP-1, suggests that at least a subset of the interactions reported here may be conserved across cell types. However, in view of the variable strength and specificity of the IFN transcriptional response across different cell types [8,9], it is likely that a subset of interactions are also cell type-specific, a possibility that warrants further investigation. Moreover, in this work, we directly stimulated cells with IFN, thus bypassing the need for cytoplasmic or endosomal sensors to trigger an IFN response. While this provides a direct basis to understand IFN-dependent interactome remodeling, future studies making use of different activating ligands, such dsRNA, lipopolysaccharide, other IFNs, or viral infection, will be required in order to define how the interactome of human cells is rewired to establish selective responses to distinct stimuli.

Charting macromolecular interaction networks in a physiologically relevant and differential context, particularly at the proteome scale, represents a long-standing challenge [16]. Our results highlight the unique power of protein correlation profiling, in combination with SILAC labeling and size exclusion chromatography, to systematically resolve interaction dynamics in the innate immune response, or in response to cellular perturbations more broadly $[17,77]$. Widely used methods for interactome mapping, such as yeast two-hybrid or affinity purification-mass spectrometry, rely on heterologous expression of fusion proteins or the introduction of a protein tag; the former removes proteins completely from their endogenous cellular context, whereas the latter can disrupt the native interactions or subcellular localization of the tagged protein [78]. Thermal proximity coaggregation (TPCA) has demonstrated promise for interrogating protein interaction networks in vivo, or across distinct cellular states [79-81], but to date has been limited to monitoring the dynamics of known interactions or protein complexes, rather than enabling de novo network inference. In contrast, the primary disadvantage associated with SEC-PCP-SILAC is its moderate bias towards proteins of greater cellular abundance [82]. In combination with the computational tools for differential network analysis described here, SEC-PCP-SILAC represents a powerful, untargeted approach to define rearrangements in the human interactome in response to cellular stimuli.

On the other hand, several limitations of SEC-PCP-SILAC, and co-fractionation approaches more generally, should be noted. Although SEC-PCP-SILAC provides a basis 
for inference of co-complex membership based on correlated protein abundance across conditions designed to separate protein complexes based on their size, it does not provide direct evidence of physical protein-protein interactions as such. Moreover, some authors have drawn a distinction between methods that detect "binary" interactions, which ostensibly represent direct biophysical contacts between protein pairs, and those that detect "co-complex" interactions, which represent all pairs of proteins in the same protein complex as physically interacting [83, 84]. Whether one type of interaction is more biologically meaningful than another has been a matter of some debate, and it is noteworthy that many literature-curated interaction databases and standardized formats for molecular interaction data do not draw such a distinction [85-87]. Nonetheless, the fact that not all of the interacting protein pairs reported by PrInCE will be in direct biophysical contact can also be viewed as a limitation of the resource presented here, although some evidence exists that direct contacts can also be recovered from the underlying protein correlation profiles using more bespoke methods [88]. A more general limitation is that our study employed a relatively lenient precision threshold of $70 \%$. While the results presented here indicate the IFN interactome has value as a resource for discovery, and for systems-level interrogation of the innate immune response, any of the individual putatively novel interactions detected here requires independent confirmation by an orthogonal experimental method to be considered reliable, as is indeed the case for any high-throughput interactome mapping technique.

To facilitate exploration of the complete dataset, we have developed an interactive web application, available at https://ifn-interactome.msl.ubc.ca, that allows users to visualize both the IFN interactome network as well as the underlying PCP chromatograms. The network view further allows users to optionally restrict the network either to specific genes that are of interest, or to entire sets of genes called as differentially expressed in transcriptomic meta-analyses of 103 different diseases, including the IFN-related diseases depicted in Fig. 3i [42, 43].

\section{Conclusions}

In sum, the map of the IFN-induced interactome presented here systematically expands our understanding on the organization of the innate immune response while complementing previous functional and systems-level studies, providing a rich resource to inform hypothesis-driven experiments. Our data reveals a surprisingly broad spectrum of rewiring in cellular pathways induced by IFN and uncovers novel regulatory mechanisms at the levels of transcription and translation that modulate the IFN response. Intersecting this network map with data from genome-wide association or exome sequencing studies could prove an effective strategy to further understand how these pathways are perturbed by common or rare variants in the context of autoimmune or neuropsychiatric diseases $[89,90]$. More broadly, our work establishes a proteomic and bioinformatic platform to delineate the complex networks of regulatory pathways activated in response to physiological or pathophysiological stimuli.

\section{Methods}

\section{Cell culture and IFN $\beta$ stimulation}

HeLa cells were cultured in Dulbecco's modified Eagle's medium (DMEM) supplemented with $10 \%$ fetal bovine serum (FBS), $1 \times$ penicillin-streptomycin (Pen-Strep), and 
$2 \mathrm{mM}$ L-glutamine at $37^{\circ} \mathrm{C}$. THP- 1 cells were cultured in RPMI- 1640 medium supplemented with $10 \%$ FBS, $0.05 \mathrm{mM}$ 2-mercaptoethanol, and $1 \times$ Pen-Strep at $37^{\circ} \mathrm{C}$. For IFN $\beta$ stimulation, cells were seeded and incubated overnight at $37^{\circ} \mathrm{C}$. The following day, cells were washed with $1 \times$ phosphate-buffered saline (PBS) and stimulated with $1000 \mathrm{U} / \mathrm{mL}$ of human recombinant IFN $\beta$ (R\&D Systems) in DMEM for the designated length of time. For SILAC experiments, cells were stimulated in the appropriate SILAC-formulated media.

\section{Plasmids and transfections}

HA-tagged IFI35 was generated as follows. First, total RNA was isolated from IFN $\beta$ stimulated (24h) HeLa cells via TRIzol extraction (Thermo Fisher) followed by RTPCR using an oligo dT primer. Desired sequences were amplified from cDNA using primers IFI35-F (5'-TAGGGTACCATGTCAGCCCCACTGGATGCCG-3') and IFI35-R (5'-TAGCTCGAGCTAGCCTGACTCAGAGGTGAAGACTGC-3'). Amplicons were digested, followed by ligation into pcDNA3.1. Subsequently, a $3 \times$ HA tag was N-terminally fused onto IFI35, respectively, by amplifying the cloned sequences with primers that incorporated the tags and subcloning into the respective constructs. Constructs were confirmed through sequencing. The ISRE-Luc reporter construct was a gracious gift from Dr. Curt Horvath (Northwestern University) and contains $5 \times$ ISG54 ISRE elements upstream of a TATA box and a firefly luciferase open reading frame.

Transfections were done as follows: briefly, $3.0 \times 10^{5}$ HeLa cells were seeded into 6well plate and incubated for $24 \mathrm{~h}$ at $37^{\circ} \mathrm{C}$. Plasmids $(2 \mu \mathrm{g})$ and transfection reagent ( $5 \mu \mathrm{L}$ of Lipofectamine 2000; Invitrogen) was added to $125 \mu \mathrm{L}$ of OptiMEM serum-free media (Thermo Fisher) in separate tubes and incubated for $5 \mathrm{~min}$. Tubes were combined and incubated for $15 \mathrm{~min}$. Media were aspirated from cells, and the $250-\mu \mathrm{L}$ transfection mix was added to cells dropwise. Complete media were added to each well, and cells were incubated at $37^{\circ} \mathrm{C}$. For RPL28 and control siRNA experiments, cells were transfected as per manufacturer's protocol at a final concentration of $25 \mathrm{nM}$ using Dharmafect I transfection reagents (Dharmacon).

\section{Luciferase assays}

Luciferase assays were carried out using a Luciferase Assay System Kit (Promega). Briefly, cells transfected in a 6-well plate as described above were harvested and washed with $1 \times$ PBS. Cells were then lysed using $1 \times$ Passive Lysis Buffer as per manufacturer's protocol (Promega). Protein concentration was then determined via Bradford assay. Equal amounts of protein $(30 \mu \mathrm{g})$ were added to a Costar Flat White 96-well plate for each condition, and samples were brought to equal volume with $1 \times$ Passive Lysis Buffer. Following this, $50 \mu \mathrm{L}$ of luciferase reagent was added to each well and luminescence was recorded on an Infinite M200 microplate reader (Tecan).

\section{Western blots}

Equal amounts of protein were resolved on a 12\% SDS-PAGE gel and then transferred to a polyvinylidene difluoride Immobilon-FL membrane (PVDF; Millipore). Membranes were blocked for $30 \mathrm{~min}$ at room temperature with 5\% skim milk in TBST $(50 \mathrm{mM}$ 
Tris, $150 \mathrm{mM} \mathrm{NaCl}, 1 \%$ Tween-20, $\mathrm{pH} 7.4)$. Blots were incubated for $24 \mathrm{~h}$ at $4{ }^{\circ} \mathrm{C}$ with the following antibodies: mouse anti-GAPDH (1:1000; AbLab), rabbit anti-HA (1:1000; Cell Signalling-C29F4), rabbit anti-RPL14 (1:1000; Bethyl Laboratories-A305-052A), rabbit anti-RPL28 (1:1000; AbCam-ab138125), mouse anti-IFIT2 (1:1000; Santa Cruz-sc-390,724), mouse anti-IFI35 (1:1000; Santa Cruz-sc-100,769), or rabbit antiNMI (1:1000; AbCam-ab183724). Membranes were washed 3 times with TBST and incubated with either IRDye $800 \mathrm{CW}$ goat anti-mouse (1:5000; Li-Cor Biosciences) or IRDye $800 \mathrm{CW}$ goat anti-rabbit (1:5000; Li-Cor Biosciences) for $1 \mathrm{~h}$ at room temperature. Membranes were then washed 3 more times with TBST before imaging on an Odyssey imager (Li-Cor Biosciences).

\section{Metabolic labeling}

HeLa cells were transfected with siFluc or siRPL28 for $48 \mathrm{~h}$ before being stimulated with IFN $\beta$ for 4 or $8 \mathrm{~h}$ and labeled with $250 \mu \mathrm{Ci}\left[{ }^{35} \mathrm{~S}\right]$-Met/Cys for $30 \mathrm{~min}$. Cells were washed twice with $1 \mathrm{~mL}$ PBS and harvested with $100 \mu \mathrm{L}$ RIPA buffer. Equal amounts of lysates were loaded on 12\% SDS-PAGE gels. Gels were dried and radioactive bands were analyzed using a phosphorimager (GE Amersham Typhoon). To quantify incorporated $\left[{ }^{35} \mathrm{~S}\right]$-Met/Cys, $20 \mu \mathrm{g}$ of protein was precipitated with $25 \%$ trichloroacetic acid (TCA) before being filtered through a glass fiber filter. Subsequently, the filter was washed three times with 5\% TCA followed by $100 \%$ acetone. The filter was suspended in scintillation fluid and analyzed on a liquid scintillation counter (Perkin Elmer).

\section{Immunofluorescence}

Cells were seeded onto coverslips in 6-well plates and allowed to adhere overnight at $37^{\circ} \mathrm{C}$. The following day, cells were transfected with the respective constructs and incubated for $24 \mathrm{~h}$ at $37^{\circ} \mathrm{C}$. Subsequently, cells were washed twice with $1 \times$ PBS and fixed with 3\% paraformaldehyde for $15 \mathrm{~min}$. Cells were washed with PBS and cells were permeabilized with $0.2 \%$ Triton X-100 in PBS for 30 min. Next, cells were blocked for 30 min with Blocking Solution (3\% BSA and 0.2\% Triton X-100 in PBS), followed by incubation with primary antibody in Blocking Solution for $1 \mathrm{~h}$ at room temperature. Cells were washed three times with $1 \times$ PBS and incubated with secondary antibodies in $2 \%$ BSA plus PBS. Following this, cells were washed three times with $1 \times$ PBS and incubated with Hoechst dye (1:20,000 in PBS) for 15 min. Finally, coverslips were washed with $1 \times$ PBS and mounted onto a slide for imaging. Slides were imaged on a Leica SP5 confocal microscope with $\mathrm{a} \times 63$ oil objective lens and $\mathrm{a} \times 2$ digital zoom. Primary antibodies used are rabbit anti-HA (1:1000, Cell Signalling-C29F4). Secondary antibodies used are anti-rabbit Texas Red (1:20,000).

\section{Polysome and ribosome isolation}

HeLa cells $\left(1.0 \times 10^{7}\right)$ were seeded in $150 \mathrm{mM}$ tissue culture plates for each condition and incubated for $24 \mathrm{~h}$ at $37^{\circ} \mathrm{C}$. Media were aspirated and replaced with either control media or media containing $1000 \mathrm{U} / \mathrm{mL}$ IFN $\beta$, and cells were incubated for $24 \mathrm{~h}$ at $37^{\circ} \mathrm{C}$ before being subjected to polysome or ribosome isolation. For whole ribosome isolation, cells were lysed with Ribosome Lysis Buffer (300 mM NaCl, $15 \mathrm{mM}$ Tris- $\mathrm{HCl}, 6$ $\mathrm{mM} \mathrm{MgCl}_{2}, 1 \%$ Triton X-100, $1 \mathrm{mg} / \mathrm{mL}$ heparin, $\left.\mathrm{pH} 7.5\right)$. Lysates were clarified by 
centrifugation at 20,000 r.c.f. for $10 \mathrm{~min}$ at $4{ }^{\circ} \mathrm{C}$. Clarified lysates were layered over a sucrose cushion at a 1:1 (v/v) ratio (2 M sucrose in Ribosome Lysis Buffer) followed by centrifugation at 100,000 r.c.f. for $24 \mathrm{~h}$ at $4{ }^{\circ} \mathrm{C}$. Pelleted ribosomes were resuspended in RIPA buffer (50 mM Tris, $150 \mathrm{mM} \mathrm{NaCl}, 0.1 \%$ SDS, $0.5 \%$ sodium deoxycholate, $1 \%$ Triton X-100, $0.5 \mathrm{mM}$ EDTA), and protein concentration was quantified by Bradford assay (BioRad). Equal amounts of protein were used for western blot analysis.

For polysome analysis, after treatment with IFN $\beta$, cycloheximide $(100 \mu \mathrm{g} / \mathrm{mL})$ was added to the media and cells were incubated for $5 \mathrm{~min}$. Cells were washed 3 times with $1 \times$ PBS plus cycloheximide $(100 \mu \mathrm{g} / \mathrm{mL})$ before being lysed in $400 \mu \mathrm{L}$ of Polysome Lysis Buffer $(300 \mathrm{mM} \mathrm{NaCl}, 15 \mathrm{mM}$ Tris- $\mathrm{HCl}, 15 \mathrm{mM} \mathrm{MgCl} 2,100 \mu \mathrm{g} / \mathrm{mL}$ cycloheximide, 1 $\mathrm{mg} / \mathrm{mL}$ heparin). Lysates were clarified by serial centrifugation at 800 r.c.f. for $5 \mathrm{~min}$ at $4{ }^{\circ} \mathrm{C}$, then 13,000 r.c.f. for $10 \mathrm{~min}$ at $4{ }^{\circ} \mathrm{C}$. RNA was quantified via NanoDrop, and equal amounts of RNA $(500 \mu \mathrm{g})$ were loaded onto a linear $10-50 \%$ sucrose gradient made in Polysome Lysis Buffer. Gradients were centrifuged in a SW41 Ti Rotor (Beckman) for $2.5 \mathrm{~h}$ at $40,000 \mathrm{RPM}$ at $4{ }^{\circ} \mathrm{C}$. Fractions were collected on a Gradient Station IP Fractionator (BioComp). Fractions $(750 \mu \mathrm{L})$ corresponding to free ribosomes (40S, 60S, and $80 \mathrm{~S}$ monosomes) and polysomes were pooled, and proteins were precipitated using trichloroacetic acid. Resulting protein pellets were reduced, alkylated, and subjected to trypsin digestion before being analyzed by LC-MS/MS.

\section{SILAC labeling and shotgun mass spectrometry}

HeLa cells were cultured in DMEM (Lys/ $\mathrm{Arg}^{-/-}$) supplemented with 10\% dialyzed FBS (Invitrogen), $1 \times$ Pen-Strep, and combinations of the following lysine and arginine isotopologues: for "light" ("L")-labeled cells, L-arginine $(84 \mathrm{mg} / \mathrm{L})$ and L-lysine $(146 \mathrm{mg} / \mathrm{L})$ (Sigma-Aldrich); for "medium" ("M")-labeled cells, ${ }^{13} \mathrm{C}_{6}$-L-arginine $(87 \mathrm{mg} / \mathrm{L})$ and $\mathrm{D}_{4}$-Llysine (150 mg/L); and for "heavy" ("H")-labeled cells, ${ }^{13} \mathrm{C}_{6}{ }^{15} \mathrm{~N}_{4}$-L-arginine $(89 \mathrm{mg} / \mathrm{L}$ ) and ${ }^{13} \mathrm{C}_{6}{ }^{15} \mathrm{~N}_{2}$-L-lysine (154 mg/L) (Cambridge Isotope Laboratories). Cells were split into each SILAC formulation and passaged six times to allow for complete incorporation of amino acid isotopologues.

For shotgun proteomic analysis, $\sim 1.0 \times 10^{7}$ cells were harvested from control (light), $4 \mathrm{~h}$ IFN $\beta$ stimulation (medium), and $24 \mathrm{~h}$ IFN $\beta$ stimulation (heavy). Cells were lysed in Lysis Buffer (4\% SDS, $10 \mathrm{mM}$ DTT, $100 \mathrm{mM}$ Tris- $\mathrm{HCl}, \mathrm{pH} 8.8$ ) and heated at $95^{\circ} \mathrm{C}$ for $5 \mathrm{~min}$. Samples were then centrifuged for $10 \mathrm{~min}$ at 16,000 r.c.f. at $4{ }^{\circ} \mathrm{C}$, and the supernatant was collected. Protein concentrations were then measured via BCA assay (Thermo Fisher). One hundred micrograms of protein from each sample (light, medium, and heavy) was combined and subjected to acetone precipitation. Protein pellets were resuspended in a $6 \mathrm{M} / 2 \mathrm{M}$ urea/thiourea mixture. Samples were reduced and alkylated by adding $6 \mu \mathrm{g}$ of DTT and $15 \mu \mathrm{g}$ of iodoacetamide and incubating at room temperature in the dark for $30 \mathrm{~min}$ and $20 \mathrm{~min}$, respectively. Three micrograms of LysC was added to each sample and incubated for $3 \mathrm{~h}$ at room temperature. Subsequently, samples were diluted with 4 volumes of Digestion Buffer $\left(50 \mathrm{mM} \mathrm{NH}_{4} \mathrm{HCO}_{3}\right)$ and trypsin (Promega) was added at a ratio of 1:50. Samples were incubated shaking overnight at room temperature. The resulting peptide supernatant was acidified to $\mathrm{pH}<2.5$ and purified using homemade Stop-and-go-extraction tips (StageTips) composed of C18 Empore material $(3 \mathrm{M})$ packed in to $200 \mu \mathrm{L}$ pipette tips [91]. StageTips were conditioned with 
methanol and equilibrated with $1 \%$ trifluoroacetic acid (TFA; loading buffer). Peptide supernatants were loaded onto the columns and washed with two bed volumes of buffer A ( $0.5 \%$ formic acid). Peptides were eluted with buffer B ( $80 \% \mathrm{MeCN}, 0.5 \%$ formic acid), dried down. Peptides from each biological replicate were then subjected to high $\mathrm{pH}$ reverse-phase (RP) fractionation on an Agilent 1100 HPLC system with an Agilent Zorbax Extend column $(1.0 \times 50 \mathrm{~mm}, 3.5 \mu \mathrm{m}$ particles, flow rate of $50 \mu \mathrm{L} / \mathrm{min})$. Dried peptides were resuspended in RP buffer A ( $\left.5 \mathrm{mM} \mathrm{NH}_{4} \mathrm{HCO}_{2}, 2 \% \mathrm{MeCN}, \mathrm{pH} 10\right)$, injected, and eluted from the column over a 60-min gradient: 0 to $5 \mathrm{~min} 6 \% \mathrm{RP}$ buffer B ( $5 \mathrm{mM}$ $\mathrm{NH}_{4} \mathrm{HCO}_{2}, 90 \% \mathrm{MeCN}$ ), 5-7 min 8\% RP buffer B, 7-45 min 27\% RP buffer B, 45-49 min $31 \%$ RP buffer B, 49-53 min 39\% RP buffer B, and 53-60 min 60\% RP buffer B. The column was washed by running 100\% RP buffer B for 5 min. Fractions were collected every $40 \mathrm{~s}$ for $60 \mathrm{~min}$. Every eighth fraction was then concatenated, dried, and resuspended in buffer A for mass spectrometry analysis.

Purified peptides were analyzed using an Easy nano LC 1000 nanoflow HPLC (Thermo Fisher) on-line coupled to a Q-Exactive mass spectrometer (Thermo Fisher). The LC was operated in a trapping mode (two column system) using a 4-cm-long, 100$\mu \mathrm{m}$-inner-diameter fused silica trap column. The analytical column was from $75-\mu \mathrm{m}-$ inner-diameter fused silica capillary, and it was either with an integrated spray tip, or it was fritted and attached to a 20- $\mu \mathrm{m}$-inner-diameter fused silica gold coated spray tip. Columns with spray tip and spray tips for fritted columns were pulled on a P-2000 laser puller from Sutter Instruments to 6- $\mu$ m-diameter opening. Added spray tips were coated on EM SCD005 Super Cool Sputtering Device (Leica). The trap column was packed with $5-\mu \mathrm{m}$-diameter Aqua C-18 beads (Phenomenex) to $2 \mathrm{~cm}$, while the analytical column was packed with 3.0- $\mu$ m-diameter Reprosil-Pur C-18-AQ beads (Dr. Maisch). The trap column was conditioned with $20 \mu \mathrm{L}$ buffer A, and the analytical column was conditioned with $4 \mu \mathrm{L}$ of the same buffer. Samples were loaded with $20 \mu \mathrm{L}$ of buffer A. The analysis was performed at $250 \mathrm{~nL} / \mathrm{min}$ over $180 \mathrm{~min}$ with a gradient from 0 to $40 \%$ buffer B over $180 \mathrm{~min}$, then from 40 to $100 \%$ over 2 min and held at $100 \%$ B over $10 \mathrm{~min}$. The LC autosampler thermostat was set at $7{ }^{\circ} \mathrm{C}$. The Q-Exactive was operated in a data-dependent mode using Xcalibur v.2.2 (Thermo Fisher) and set to acquire a full-range scan at 70,000 resolution from 350 to 2000 Th (AGC target 3E6) and to fragment the top ten multiply charged ions above $5 \%$ underfill ratio by HCD (resolution 17,500, AGC target 1E5, maximum injection time $60 \mathrm{~ms}$, NCE 28) in each cycle. Parent ions were then excluded from MS/MS for the next $25 \mathrm{~s}$. Error of mass measurement is typically within $5 \mathrm{ppm}$ and was not allowed to exceed $10 \mathrm{ppm}$.

\section{SEC-PCP-SILAC sample preparation}

Cell lysis and size exclusion chromatography were performed as previously described [17, 77], with minor modifications. Briefly, after $24 \mathrm{~h}$ treatment with IFN $\beta$, cells were immediately harvested by centrifugation at 200 r.c.f. for $5 \mathrm{~min}$ at $4{ }^{\circ} \mathrm{C}$ and washed three times with ice-cold $1 \times$ PBS. Cells of the same SILAC label were pooled and resuspended in $3 \mathrm{~mL}$ of ice-cold size-exclusion chromatography (SEC) buffer $[50 \mathrm{mM} \mathrm{KCl}, 50 \mathrm{mM} \mathrm{NaCH} 3 \mathrm{COO}$, $50 \mathrm{mM}$ Tris, pH 7.2, containing 1× EDTA-free HALT protease \& phosphatase inhibitor cocktail (Thermo Fisher)]. Cells were lysed via Dounce homogenization for $2.5 \mathrm{~min}$, and insoluble material was removed by ultracentrifugation at 100,000 r.c.f. for $15 \mathrm{~min}$ at $4{ }^{\circ} \mathrm{C}$. 
Subsequently, the supernatants were concentrated over a 100-kDa molecular weight cutoff spin column (Sartoris Stedim, Goettingen, Germany). Equal amounts of protein from heavy-labeled and medium-labeled lysates were combined and immediately injected into a chromatography systems with two $300 \times 7.8 \mathrm{~mm}$ BioSep4000 Columns (Phenomenex) equilibrated with SEC buffer. Samples were collected into 80 fractions by a 1200 Series analytical HPLC (Agilent Technologies) at a flow rate of $0.5 \mathrm{~mL} / \mathrm{min}$ at $8{ }^{\circ} \mathrm{C}$. To avoid aggregated proteins and small monomers, only fractions $6-65$, corresponding to molecular weights $\sim 2 \mathrm{mDa}-65 \mathrm{kDa}$ as approximated by the use of common standards thyroglobulin, apoferritin, and bovine serum albumin (Sigma-Aldrich), were submitted for LC-MS/ MS analysis and utilized for PCP. The light-labeled SILAC lysates consisted of unstimulated and IFN-stimulated cells to serve as an internal standard. These samples were independently separated by SEC from the medium/heavy samples. To generate the light reference mixture, fractions 6-65 were pooled and spiked equally into each of the corresponding medium/heavy fractions at a volume of 1:0.75 (medium/heavy to light). A urea/ thiourea mix was added to protein fractions to create a final concentration of $6 \mathrm{M} / 2 \mathrm{M}$ urea/thiourea. Samples were reduced and alkylated by adding $6 \mu \mathrm{g}$ of DTT and $15 \mu \mathrm{g}$ of iodoacetamide and incubating at room temperature in the dark for $30 \mathrm{~min}$ and $20 \mathrm{~min}$, respectively. Three micrograms of LysC was added to each sample and incubated for $3 \mathrm{~h}$ at room temperature. Subsequently, samples were diluted with 4 volumes of Digestion Buffer $\left(50 \mathrm{mM} \mathrm{NH}_{4} \mathrm{HCO}_{3}\right)$ and trypsin (Promega) was added at a ratio of 1:50. Samples were incubated shaking overnight at room temperature. The resulting peptides were purified via STAGE tips.

\section{Immunoprecipitation mass spectrometry sample preparation}

HeLa cell lysates subjected to IP-MS analysis were prepared similarly as described for SEC-PCP-SILAC, apart from isotopologue labeling. In short, control and IFN-stimulated HeLa were harvested via centrifugation at 200 r.c.f. for $5 \mathrm{~min}$ at $4{ }^{\circ} \mathrm{C}$, then washed three times with ice-cold PBS. Cells were then lysed via Dounce homogenization in SEC buffer followed by centrifugation at 100,000 r.c.f. Supernatants were concentrated over a 100kDa molecular weight cutoff spin column (Sartoris Stedim, Goettingen, Germany). Protein concentration was determined by NanoDrop (Thermo Fisher). Two hundred fifty micrograms of protein from control or IFN-stimulated samples was diluted to $500 \mu \mathrm{L}$ in SEC buffer and incubated with the desired antibody or IgG as a control overnight at $4{ }^{\circ} \mathrm{C}$. Antibody concentrations were used as follows: mouse anti-IFI35 (1:50; Santa Cruz-sc100769), rabbit anti-NMI (1:50; AbCam-ab183724), mouse anti-STAT1 (1:50; AbCamab3987), and mouse anti-PNPT1 ( $2 \mu \mathrm{g}$; Santa Cruz-ab-271,479). Protein A/G Magnetic beads ( $25 \mu \mathrm{L}$; Thermo Fisher) pre-washed with SEC buffer were added to the samples and incubated $1 \mathrm{~h}$ at room temperature. Beads were washed three times with $20 \times$ bed volume of SEC buffer. Samples were then subjected to an on-bead in-solution trypsin digestion. Peptides were purified by STAGE tips.

\section{Tandem liquid chromatography mass spectrometry of SEC-PCP-SILAC and LFQ samples}

Purified peptides were analyzed using a quadrupole time of flight mass spectrometer (Impact II; Bruker Daltonics) on-line coupled to an Easy nano LC 1000 HPLC (Thermo Fisher) using nanoBooster with methanol and a Captive spray nanospray ionization 
source (Bruker Daltonics) including a 2-cm-long, 100- $\mu \mathrm{m}$-inner-diameter fused silica fritted trap column, and 40-cm-long, 75- $\mu \mathrm{m}$-inner-diameter fused silica analytical column with an integrated spray tip (6-8- $\mu$ m-diameter opening, pulled on a P-2000 laser puller from Sutter Instruments). The trap column was packed with $5 \mu \mathrm{m}$ Aqua C-18 beads (Phenomenex) while the analytical column was packed with $1.9-\mu \mathrm{m}$-diameter Reprosil-Pur C-18-AQ beads (Dr. Maisch). Buffer A consisted of $0.1 \%$ aqueous formic acid, and buffer B consisted of $0.1 \%$ formic acid in acetonitrile. Samples were resuspended in buffer A and loaded with the same buffer. Standard 90-min gradients were from $0 \%$ B to $35 \%$ B over $90 \mathrm{~min}$, then to $100 \%$ B over 2 min, held at $100 \%$ B for 15 min. Before each run, the trap column was conditioned with $20 \mu \mathrm{L}$ buffer $\mathrm{A}$, the analytical with $4 \mu \mathrm{L}$ of the same buffer, and the sample loading was set at $20 \mu \mathrm{L}$ (for samples up to $13 \mu \mathrm{L}$ volume). The $\mathrm{LC}$ thermostat temperature was set at $7^{\circ} \mathrm{C}$. The Captive Spray Tip holder was modified similarly to an already described procedure [92]. The fused silica spray capillary was removed (together with the tubing which holds it) to reduce the dead volume, and the analytical column tip was fitted in the Bruker spray tip holder using a piece of $1 / 16$ in $\times 0.015$ PEEK tubing (IDEX), an 1/16 in metal two-way connector, and a 16-004 Vespel ferrule. The sample was loaded on the trap column at $850 \mathrm{Bar}$, and the analysis was performed at $0.25 \mu \mathrm{L} / \mathrm{min}$ flow rate. The Impact II was set to acquire in a data-dependent auto-MS/MS mode with inactive focus fragmenting the 20 most abundant ions (one at a time at $18 \mathrm{~Hz}$ rate) after each full-range scan from $\mathrm{m} / \mathrm{z} 200 \mathrm{Th}$ to $\mathrm{m} / \mathrm{z} 2000 \mathrm{Th}$ (at $5 \mathrm{~Hz}$ rate). The isolation window for MS/MS was 2 to 3 Th depending on parent ion mass to charge ratio, and the collision energy ranged from 23 to $65 \mathrm{eV}$ depending on ion mass and charge [92]. Parent ions were then excluded from MS/MS for the next $0.4 \mathrm{~min}$ and reconsidered if their intensity increased more than 5 times. Singly charged ions were excluded since in ESI mode peptides usually carry multiple charges. Strict active exclusion was applied. Error of mass measurement is typically within $5 \mathrm{ppm}$ and was not allowed to exceed $10 \mathrm{ppm}$. The nano ESI source was operated at $1900 \mathrm{~V}$ capillary voltage, 0.20 Bar nanoBooster pressure, $3 \mathrm{~L} /$ min drying gas, and $150{ }^{\circ} \mathrm{C}$ drying temperature. The cross connector between the trap column, waste out capillary, and analytical column was grounded via a $0.4-\mathrm{mm}$ platinum wire to prevent electrical corrosion of the LC S valve.

Mass spectrometry of HeLa cells after siRNA knockdown of RPL28, RPS26, or RPS28 was conducted as follows: peptide samples were purified by solid phase extraction on C-18 stage tips.

Purified peptides were analyzed using a timsTOF trapped ion mobility quadrupole time of flight mass spectrometer (timsTOF Pro; Bruker Daltonics) on-line coupled to an Easy nano LC 1000 HPLC (Thermo Fisher Scientific) using a Captive spray nanospray ionization source (Bruker Daltonics) including a 75- $\mu \mathrm{m}$-inner-diameter, 40-cmlong fused silica analytical column with an integrated spray tip (6-8- $\mu$ m-diameter opening, pulled on a P-2000 laser puller from Sutter Instruments). The analytical column was packed with 1.9- $\mu$ m-diameter Reprosil-Pur C-18-AQ beads (Dr. Maisch), and it was heated to $50^{\circ} \mathrm{C}$ using tape heater (SRMU020124, Omega) and in house built temperature controller with a temperature sensor (SA1-RTD-80, Omega) and a microprocessor controller (CN7500, Omega). Buffer A consisted of $0.1 \%$ aqueous formic acid and $2 \%$ acetonitrile in water, and buffer B consisted of $0.1 \%$ formic acid in $90 \%$ acetonitrile in water. Samples were resuspended in buffer A and loaded with the same buffer. 
The gradient was from $5 \%$ B to $15 \%$ B over $60 \mathrm{~min}$, then to $37 \%$ B from 60 to $120 \mathrm{~min}$, then to $90 \%$ B over 2 min, held at $90 \%$ B for 13 min. Before each run, the analytical column was conditioned with $4 \mu \mathrm{L}$ of buffer A and the sample loading was set at $10 \mu \mathrm{L}$ (for samples up to $3 \mu \mathrm{L}$ volume). The $\mathrm{LC}$ thermostat temperature was set at $7^{\circ} \mathrm{C}$. The Captive Spray Tip holder was modified similarly to a previously described procedure [93]: the fused silica spray capillary was removed, together with the tubing which holds it, to reduce the dead volume, and the analytical column tip was fitted in the Bruker spray tip holder using a piece of 1/16 in $\times 0.015$ PEEK tubing (gray PEEK, IDEX), an 1/ 16 in metal two way connector, and a 16-004 Vespel ferrule (Trajan Scientific). The sample was loaded on the trap column at 950 Bar, and the analysis was performed at $0.35 \mu \mathrm{L} / \mathrm{min}$ flow rate. timsTOF was run with OTOF Control v. 5.1 (Bruker). LC and MS were controlled with HyStar 4.1 (4.1.21.1, Bruker). The timsTOF was set to acquire in a data-dependent PASEF mode with fragmenting the 10 most abundant ions (one at the time at $18 \mathrm{~Hz}$ rate) after each full-range scan from m/z $100 \mathrm{Th}$ to $\mathrm{m} / \mathrm{z} 1700 \mathrm{Th}$. The collision energy was $42 \mathrm{eV}$. Parent ions were then excluded from MS/MS for the next $0.4 \mathrm{~min}$ and reconsidered if their intensity increased more than 5 times. Error of mass measurement was not allowed to exceed $10 \mathrm{ppm}$. The nano ESI source was operated at $1900 \mathrm{~V}$ capillary voltage, $3 \mathrm{~L} / \mathrm{min}$ drying gas, and $180^{\circ} \mathrm{C}$ drying temperature. Funnel 1 was set at $300 \mathrm{~V}$, funnel 2 at $200 \mathrm{~V}$, multipole RF at $200 \mathrm{~V}$, deflection delta at $70 \mathrm{~V}$, quadrupole ion energy at $5 \mathrm{eV}$, low mass at $200 \mathrm{Th}$, collision cell energy at $10 \mathrm{eV}$, collision RF at $1500 \mathrm{~V}$, transfer time at $60 \mu \mathrm{s}$, and pre-pulse storage at $12 \mu \mathrm{s}$. PASEF was on with 10 PASEF scans for charges 0 to 4, target intensity 20,000 and intensity threshold 2500. Singly charged ions were filtered off using tims filtering polygon set on the timsTOF heatmap. Isolation width was 2 Th for $\mathrm{m} / \mathrm{z} \leq 700$ Th and 3 Th for $\mathrm{m} / \mathrm{z} \geq$ $800 \mathrm{Th}$; collision energy was $42.0 \mathrm{eV}$. MS/MS repetition was 1 for intensity > 20,000, 2 for intensity 14,142 to $20,000,3$ for intensity 11,547 to 14,142 , 4 for intensity 10,000 to 11,547, 5 for intensity 8944 to $10,000,6$ for intensity 8164 to 8944,7 for intensity 7559 to 8164,8 for intensity 7071 to 7559,9 for intensity 6666 to 7071, and 10 for lower intensity. Exclusion window had mass width $0.015 \mathrm{Th}$ and $1 / \mathrm{K} 0$ width $0.015 \mathrm{~V} . \mathrm{s} / \mathrm{cm}^{2}$.

\section{Protein identification and quantification}

Protein identification and quantification was performed using MaxQuant version 1.5.3.30 [94, 95]. The data were searched against the Homo sapiens UniProt database [96]. For shotgun SILAC experiments, the following parameters were used: peptide mass accuracy, $20 \mathrm{ppm}$ (ppm) for first search, $10 \mathrm{ppm}$ for second search; trypsin enzyme specificity, fixed modifications, carbamidomethyl; variable modifications, methionine oxidation, deamidation (NQ), and $\mathrm{N}$-acetylation (protein $\mathrm{N}$-terminus); and all other parameters as preset. For SEC-PCP-SILAC experiments, the following parameters were used: peptide mass accuracy, $10 \mathrm{ppm}$; fragment mass accuracy, $0.05 \mathrm{Da}$; trypsin enzyme specificity; fixed modifications, carbamidomethyl; and variable modifications, methionine oxidation, deamidation (NQ), and N-acetylation (protein N-terminus). For shotgun SILAC and SEC-PCP-SILAC experiments, both the requantify and match between run options were enabled. For SEC-PCP-SILAC experiments, SILAC labels with a minimum ratio count of one were included. For immunoprecipitation experiments, label-free quantitation (LFQ) was enabled, with a minimum ratio count of two. For 
analysis of purified ribosome composition, LFQ was enabled with a minimum ratio count of one, due to the small size of ribosomal proteins. Only those peptides exceeding the individually calculated $99 \%$ confidence limit (as opposed to the average limit for the whole experiment) were considered as accurately identified. In all analyses, contaminants and reverse hits were removed using Perseus version 1.6.1.1 [97].

For timsTOF data, analysis was performed using MaxQuant 1.6.10.43. The search was performed against a database comprised of the protein sequences from the source organism plus common contaminants using the following parameters: peptide mass accuracy $10 \mathrm{ppm}$, fragment mass accuracy $0.05 \mathrm{Da}$, trypsin enzyme specificity, fixed modifications-carbamidomethyl, and variable modifications-methionine oxidation and Nacetyl peptides. Only those peptides exceeding the individually calculated $99 \%$ confidence limit (as opposed to the average limit for the whole experiment) were considered as accurately identified.

\section{Data analysis for shotgun proteomics of the IFN response}

Differentially expressed proteins were identified using the one-sample moderated $t$ tests implemented in limma [98], followed by Benjamini-Hochberg correction. Enriched Gene Ontology terms were identified for proteins with significant differential expression between conditions at 5\% FDR using the conditional hypergeometric test [99] implemented in the GOstats R package [100], with terms from each branch of the ontology analyzed separately. Enrichment for protein-protein interactions between differentially expressed proteins was assessed using the InBioMap database [19]. The likelihood of the observed number of interactions between differentially expressed proteins was evaluated by randomly rewiring the InBioMap interactome 100 times using a degree-preserving algorithm [23] in order to maintain network topology, with the number of iterations for the edge rewiring algorithm set to $6.9 \times$ the number of edges in each network [101]. Network analyses were implemented in the R package "igraph."

\section{Removal of high-magnitude errors in protein quantitation}

Errors in quantitation of either the heavy or light channel can lead to the introduction of spurious outliers into PCP-SILAC chromatograms. To minimize the impact of these outliers on downstream analysis of the PCP chromatogram matrices, we applied a recently developed algorithm, "MODERN" (Model-free Outlier detection for Robust Networks), to remove outliers prior to network reconstruction (Skinnider et al., unpublished data). The motivating assumption that underlies MODERN is that a single observation should not globally rewire the interaction profile of a protein across the entire network. The interaction profile of each protein is quantified in MODERN as the vector of Pearson's correlation coefficients between that protein and all other proteins in the network. Each point in the chromatogram is removed in turn, and the interaction profile is recalculated upon removal of each point. The correlation between the original interaction profile and the interaction profile with a single point removed is defined as the autocorrelation. Autocorrelation statistics are converted to $z$ scores, and outliers are defined as observations associated with an autocorrelation $z$ score less than the normal distribution $z$ score corresponding to a two-tailed familywise error rate of 0.05 , given the total number of points observed. Application of 
MODERN to the six PCP chromatogram matrices led to the removal of 1308 of 245, 841 protein quantifications $(0.53 \%)$. MODERN is available as an $\mathrm{R}$ package from https://github.com/fosterlab/modern.

\section{Protein-protein interaction network reconstruction}

High-confidence protein-protein interaction networks were reconstructed from raw SEC-PCP-SILAC profiles using PrInCE [32], our open-source pipeline for cofractionation data analysis, available at https://github.com/FosterLab/PrInCE. PrInCE first implements basic data cleaning and filtering functionality to restrict analysis to high-quality chromatograms. Briefly, single missing values are imputed as the mean of the two neighboring points, proteins with fewer than five observations are removed, and a sliding average with a width of five fractions is used to smooth the chromatogram. PrInCE then fits a mixture of one to five Gaussians to the smoothed chromatograms, performs model selection using the bias-corrected Akaike information criterion [102], and discards chromatograms that could not be fit by a mixture of Gaussians. A machine-learning procedure is then used to assign an interaction score to each pair of co-fractionation profiles using a naive Bayes classifier. Features used by the classifier include the Pearson correlation of the raw chromatograms and its corresponding $p$ value, the Euclidean distance between the raw chromatograms, the Pearson correlation of the smoothed chromatograms, the number of fractions separating the maximal values of each chromatogram, and the smallest Euclidean distance between any pair of fitted Gaussians. PrInCE concatenates features from each replicate but processes each isotope channel separately, providing a total of eighteen features to two naive Bayes classifiers. Importantly, unlike other published approaches, all features provided to the classifier are derived solely from the data and do not incorporate prior biological knowledge, providing greater power for novel interaction discovery [38].

In addition to the features calculated from the co-fractionation data, the naive Bayes classifier requires sets of true positive (TP) and false positive (FP) interactions as training data. Previously, we have observed that many known protein-protein interactions cataloged in literature-curated databases are highly assay- or context-specific, and developed a "universal gold standard" subset of the CORUM database [28] tailored to predicting interactions from co-fractionation data [40]. This subset was used to train the classifier, with intra-complex interactions considered true positives and inter-complex interactions considered true negatives, using tenfold cross-validation and taking the medium of all folds as the final interaction score. The naive Bayes classifier assigns an interaction probability to every pair and returns a ranked list with putative interactions ordered by their interaction probability. The precision of the network was calculated at each point in the ranked list as the ratio of true positives to true positives and true negatives among interactions at that probability or higher, and we retained control and stimulated networks at $70 \%$ precision.

\section{Validation of the biological relevance of the IFN interactome}

To validate the biological relevance of the protein-protein interaction networks recovered by PrInCE, we assembled an aggregate network including unique interactions found in either the medium or heavy isotopologue channels at $70 \%$ precision and compared the 
aggregate network to randomly rewired networks using a degree-preserving algorithm as described above. Human Gene Ontology annotations [103] were obtained from the UniProt-GOA database [104] and processed with the R package "ontologyIndex" [105]. Annotations with the evidence codes "IPI" (inferred from physical interaction), "IEA" (inferred from electronic annotation), "NAS" (non-traceable author statement), or "ND" (no biological data), or the qualifier "NOT," were removed, and annotations were propagated up the GO hierarchy. Very broad GO terms (annotated to more than 100 proteins) were removed, and the total proportion of interacting protein pairs sharing at least one GO term in each ontological category (biological process, cellular compartment, molecular function) was calculated for both rewired and observed networks. The distribution of interacting pairs sharing at least one GO term in each category among randomized networks was used to calculate an empirical $p$ value for the observed enrichment. The same procedure was followed to evaluate the tendency of interacting protein pairs to be associated with the same disease, using disease genes obtained from the Mouse Genome Database [106] and mapped to their human orthologs using InParanoid [48]. The tendency of interacting protein pairs to contain domains known to physically interact in a highresolution three-dimensional structure was similarly assessed using domain-domain interactions obtained from the 3did database [39], with Pfam domain annotations obtained from UniProt [96]. Co-expression of protein pairs was calculated using the tissue proteome dataset described by [107]. Phylogenetic profiles were constructed using the InParanoid database ([48], with the similarity in phylogenetic profile of a protein pair defined as the Pearson correlation between the binary presence/absence vectors of each protein across all species [108]. To quantify the proportion of novel interactions in the stimulated vs. unstimulated conditions, known interactions were compiled from eighteen databases, including BIND [109], BioGRID [110], CORUM [28], DIP [111], HINT [112], HIPPIE [113], HPRD [114], IID [115], InBioMap [19], InnateDB [41], MatrixDB [116], Mentha [117], MINT [118], MPPI [119], NetPath [120], PINA [121], Reactome [122], and WikiPathways [123]. Only human interactions were retained, and self-interactions were excluded. From pathway databases and InnateDB, only the subset of information cataloging physical PPIs was retained. Gene and protein identifiers used to catalog interactions in these databases were mapped to UniProt accessions using identifier mapping files distributed by UniProt. Differential expression results from meta-analyses of 103 diseases were obtained from the MetaSignature web application (http://metasignature.stanford.edu/) $[42,43]$. To specifically evaluate the relevance of IFN stimulation to mapping interactions for genes dysregulated at the transcriptional level in these diseases, we compared the likelihood of genes that were upregulated at a 1\% FDR participating in interactions detected only after IFN stimulation as compared to all other interactions detected by SEC-PCPSILAC, and to the complete set of literature-curated human interactions, and assessed statistical significance using a $z$ test of the log-odds ratio.

\section{Functional analysis of the IFN interactome}

To quantify functional differences between the IFN-stimulated and unstimulated interactomes, we developed a permutation-based statistical test at the network level (Fig. S7A). Briefly, for each term in the Gene Ontology, we identified all proteins annotated with that term, then calculated the total number of interactions in the stimulated and 
unstimulated networks between these proteins, and the difference between the two networks. We then randomly rewired both control and stimulated networks 1000 times using a degree-preserving algorithm and calculated the difference in randomized networks. The null distribution of the randomized networks was used to calculate a $z$ score, which was subsequently converted to a probability and adjusted for multiple hypothesis testing using the method of Benjamini and Hochberg. To compare the enriched GO terms identified by this approach to those based on the protein content of the stimulated and unstimulated networks, we additionally calculated, for each GO term, the odds of proteins in each network being annotated with that term, and tested for enrichment using the $z$ score of the log-odds ratio. GO terms with statistically significant differences between stimulated and unstimulated networks at 10\% FDR were visualized as an enrichment map [52] using the "ggnetwork" package [124] and the Fruchterman-Reingold layout algorithm [125], as implemented in "igraph." Edges were drawn between GO terms on the basis of the complete set of proteins each was annotated to if the Jaccard index was greater than 0.33. For select terms, we additionally plotted the distribution of differences in number of interactions in randomized networks as a histogram.

Autocorrelations were calculated as the Pearson correlation between pairs of stimulated and unstimulated chromatograms, normalized to $z$ scores, and aggregated across all three replicates using Stouffer's method. $\mathrm{dN} / \mathrm{dS}$ ratios between human and mouse genes were obtained from Ensembl BioMart [126]. The total proportion of species in which an ortho$\log$ of each gene was present was quantified using the InParanoid database [48]. pLI scores were obtained from ExAC [49] and quantile normalized. Partial Spearman's correlations between autocorrelation and $\mathrm{dN} / \mathrm{dS}$, phylogenetic breadth, and pLI, controlling for $\log _{2}-$ fold change as observed in the shotgun proteomics dataset, were calculated using the $\mathrm{R}$ package "ppcor" [127]. To assess whether the observed rank correlations were sensitive to outliers at the level of the SEC-PCP-SILAC chromatograms, we additionally calculated the Spearman correlation after sampling with replacement from the raw chromatograms 1000 times, and recalculating the autocorrelation $z$ score between stimulated and unstimulated protein correlation profiles.

\section{Evolutionary analysis of IFN-stimulated genes}

Core, conserved, and species-specific ISGs were obtained from Shaw et al. [7], on the basis of upregulation in all vertebrates studied, in human and at least one other species, and in human only, respectively. The statistical significance of the difference between distributions of Pearson's correlations of raw PCP chromatograms in the unstimulated and stimulated conditions was assessed using a Brunner-Munzel test; correlations based on fewer than five pairwise observations were excluded from analysis. Co-immunoprecipitations from stimulated and unstimulated cells were compared using limma [98], and enrichment for different classes ISGs in immunoprecipitations of stimulated cells was assessed by gene set enrichment analysis [128], as implemented in the R package "fgsea" [129].

\section{Analysis of siRPL28 knockdown data}

Time-course transcriptome profiles of mouse ISGs in $\mathrm{CD} 19^{+} \mathrm{B}$ lymphocytes were obtained from [8]. These profiles were normalized by maximum expression across all 
timepoints, as in the original analysis; mapped to their human orthologs using InParanoid [48]; and matched to proteins that were differentially expressed after $4 \mathrm{~h}$ or $24 \mathrm{~h}$ of IFN stimulation in our shotgun proteomics data. Analysis of the siRPL28 SILAC proteomics dataset required proteins to be quantified in both the heavy and medium channels in at least two of three replicates. Protein ratios were log-transformed and compared between siRPL28-treated and untreated, IFN-stimulated cells using the moderated $t$ test implemented in limma [98]. A consensus set of ISGs was defined as those upregulated in human and at least four other species (five of ten species total) in the Shaw et al. dataset, although the observed enrichment was insensitive to the precise number of species used to define this set. The enrichment for ISGs among up- or downregulated proteins was assessed by gene set enrichment analysis [128], as implemented in the R package "fgsea" [129]. The abundance profiles of selected ISGs were plotted after normalization by subtraction of mean abundance and division by the standard deviation.

\section{Supplementary information}

Supplementary information accompanies this paper at https://doi.org/10.1186/s13059-020-02050-y.

Additional file 1. Supplementary figures S1-S10

Additional file 2. Shotgun proteomic SILAC ratios of IFN-stimulated cells at $4 \mathrm{~h}$ or $24 \mathrm{~h}$ IFN treatment.

Additional file 3. GO term enrichment on significantly changed SILAC ratios of IFN-stimulated cells at $4 \mathrm{~h}$ or $24 \mathrm{~h}$ IFN treatment.

Additional file 4. SEC-PCP-SILAC interactomes of unstimulated and IFN-stimulated HeLa cells at $70 \%$ precision.

Additional file 5. Representation of known CORUM protein complexes in the IFN interactome.

Additional file 6. Autocorrelation z scores between pairs of stimulated and unstimulated chromatograms.

Additional file 7. Gene Ontology terms differentially enriched between unstimulated and IFN-stimulated interactomes.

Additional file 8. Immunoprecipitation-mass spectrometry of four core ISGS (IFI35, STAT1, NMI, and PNPT1) in IFNstimulated and unstimulated cells.

Additional file 9. Label-free quantitation intensities of ribosomal proteins in monosomes and polysomes.

Additional file 10. Shotgun proteomic SILAC ratios of siRPL28-treated cells plus IFN for $8 \mathrm{~h}$.

Additional file 11. Gene set enrichment analysis of SILAC ratios in siRPL28-treated and IFN-stimulated cells compared to untreated controls.

Additional file 12. Label-free proteomics of IFN-stimulated cells treated with siRNAs targeting RPL28, RPS26, RPS28, or control siRNAs.

Additional file 13. Review History.

\section{Acknowledgements}

We thank Nichollas Scott (University of Melbourne) for advice on experimental design and assistance in shotgun proteomics data acquisition, Kyung-Mee Moon for assisting with manuscript preparation, and Jibin Sadasivan for help with confocal microscopy. We thank Dr. Curt Horvath (Northwestern University) for the $5 \times$ ISRE-Fluc reporter construct. We thank the members of the Foster lab for invaluable discussions.

Peer review information

Tim Sands was the primary editor on this article and managed its editorial process and peer review in collaboration with the rest of the editorial team.

Review history

The review history is available as Additional file 13.

\section{Authors' contributions}

Conceptualization, C.H.K, M.A.S., and L.J.F.; methodology, C.H.K., M.A.S., and L.J.F.; software, M.A.S. and R.G.S.; validation, C.H.K., M.A.S., A.M.M., and D.D.T.A.; formal analysis, M.A.S. and C.H.K.; investigation, C.H.K., M.A.S., A.M.M, D.D.T.A., and Q.W.T.C.; resources, E.J. and L.J.F.; writing —original draft, C.H.K., M.A.S., and L.J.F.; writing, reviewing, and editing, C.H.K. M.A.S., A.M.M, D.D.T.A., Q.W.T.C., N.S., R.G.S., E.J., and L.J.F.; supervision, E.J. and L.J.F.; funding acquisition, E.J. and L.J.F. All authors read and approved the final manuscript. 


\section{Funding}

This work was supported by Canadian Institutes of Health Research (CIHR) grant and National Sciences and Engineering Research Council (NSERC) Discovery grants awarded to L.J.F. and E.J. C.H.K. was supported by an NSERC Postgraduate Scholarship and a UBC Four Year Fellowship. M.A.S. is supported by a CIHR Vanier Canada Graduate Scholarship, an Izaak Walton Killam Memorial Pre-Doctoral Fellowship, a UBC Four Year Fellowship, and a Vancouver Coastal Health-CIHR-UBC MD/PhD Studentship. D.D.T.A. is supported by NSERC Postgraduate Scholarship and a UBC Four Year Fellowship. Mass spectrometry infrastructure used here was supported by Genome Canada/Genome BC (214PRO).

\section{Availability of data and materials}

The mass spectrometry proteomics data have been deposited to the ProteomeXchange Consortium [130] via the PRIDE partner repository [131] with the dataset identifier PXD013809 [132]. In addition, processed chromatograms for each replicate have been deposited to the EMBL-EBI BioStudies database [133], with accession S-BSST254 [134].

\section{Ethics approval and consent to participate}

Not applicable.

\section{Consent for publication}

Not applicable.

\section{Competing interests}

The authors have no competing interests.

\section{Author details}

${ }^{1}$ Michael Smith Laboratories, University of British Columbia, Vancouver, BC V6T 1Z4, Canada. ${ }^{2}$ Department of Biochemistry and Molecular Biology, University of British Columbia, Vancouver, BC V6T 1Z3, Canada. ${ }^{3}$ Current Address: Department of Genetics, Stanford University, Stanford, CA 94305, USA.

Received: 30 August 2019 Accepted: 20 May 2020

Published online: 15 June 2020

\section{References}

1. Sadler AJ, Williams BRG. Interferon-inducible antiviral effectors. Nat Rev Immunol. 2008:8:559-68. https://doi.org/10.1038/ nri2314.

2. Der SD, Zhou A, Williams BR, Silverman RH. Identification of genes differentially regulated by interferon alpha, beta, or gamma using oligonucleotide arrays. Proc Natl Acad Sci U S A. 1998;95:15623-8. https://doi.org/10.1073/pnas.95.26. 15623.

3. Ivashkiv LB, Donlin LT. Regulation of type I interferon responses. Nat Rev Immunol. 2014;14:36-49. https://doi.org/10. 1038/nri3581.

4. Crow MK, Olferiev M, Kirou KA. Type I interferons in autoimmune disease. Annu Rev Pathol. 2019;14:369-93. https://doi. org/10.1146/annurev-pathol-020117-043952.

5. Lee-Kirsch MA. The type I interferonopathies. Annu Rev Med. 2017;68:297-315. https://doi.org/10.1146/annurev-med050715-104506.

6. Schneider WM, Chevillotte MD, Rice CM. Interferon-stimulated genes: a complex web of host defenses. Annu Rev Immunol. 2014;32:513-45. https://doi.org/10.1146/annurev-immunol-032713-120231.

7. Shaw AE, Hughes J, Gu Q, Behdenna A, Singer JB, Dennis T, et al. Fundamental properties of the mammalian innate immune system revealed by multispecies comparison of type I interferon responses. PLoS Biol. 2017;15:e2004086. https://doi.org/10.1371/journal.pbio.2004086.

8. Mostafavi S, Yoshida H, Moodley D, LeBoité H, Rothamel K, Raj T, et al. Parsing the interferon transcriptional network and its disease associations. Cell. 2016;164:564-78. https://doi.org/10.1016/j.cell.2015.12.032

9. Hagai T, Chen X, Miragaia RJ, Rostom R, Gomes T, Kunowska N, et al. Gene expression variability across cells and species shapes innate immunity. Nature. 2018;563:197-202. https://doi.org/10.1038/s41586-018-0657-2.

10. Schoggins JW, Wilson SJ, Panis M, Murphy MY, Jones CT, Bieniasz P, et al. A diverse range of gene products are effectors of the type I interferon antiviral response. Nature. 2011;472:481-5. https://doi.org/10.1038/nature09907.

11. Schoggins JW, MacDuff DA, Imanaka N, Gainey MD, Shrestha B, Eitson JL, et al. Pan-viral specificity of IFN-induced genes reveals new roles for CGAS in innate immunity. Nature. 2014;505:691-5. https://doi.org/10.1038/nature12862.

12. Liu S-Y, Sanchez DJ, Aliyari R, Lu S, Cheng G. Systematic identification of type I and type II interferon-induced antiviral factors. Proc Natl Acad Sci U S A. 2012;109:4239-44. https://doi.org/10.1073/pnas.1114981109.

13. Kane M, Zang TM, Rihn SJ, Zhang F, Kueck T, Alim M, et al. Identification of interferon-stimulated genes with antiretroviral activity. Cell Host Microbe. 2016;20:392-405. https://doi.org/10.1016/j.chom.2016.08.005.

14. Fortelny N, Overall CM, Pavlidis P, Freue GVC. Can we predict protein from mRNA levels? Nature. 2017:547:E19-20. https://doi.org/10.1038/nature22293.

15. Franks A, Airoldi E, Slavov N. Post-transcriptional regulation across human tissues. PLoS Comput Biol. 2017;13:e1005535. https://doi.org/10.1371/journal.pcbi.1005535.

16. Ideker T, Krogan NJ. Differential network biology. Mol Syst Biol. 2012;8:565. https://doi.org/10.1038/msb.2011.99.

17. Kristensen AR, Gsponer J, Foster $\sqcup$. A high-throughput approach for measuring temporal changes in the interactome. Nat Methods. 2012;9:907-9. https://doi.org/10.1038/nmeth.2131.

18. Liu Y, Beyer A, Aebersold R. On the dependency of cellular protein levels on mRNA abundance. Cell. 2016;165:535-50. https://doi.org/10.1016/j.cell.2016.03.014.

19. Li T, Wernersson R, Hansen RB, Horn H, Mercer J, Slodkowicz G, et al. A scored human protein-protein interaction network to catalyze genomic interpretation. Nat Methods. 2017;14:61-4. https://doi.org/10.1038/nmeth.4083. 
20. Wu D, Sanin DE, Everts B, Chen Q, Qiu J, Buck MD, et al. Type 1 interferons induce changes in core metabolism that are critical for immune function. Immunity. 2016;44:1325-36. https://doi.org/10.1016/j.immuni.2016.06.006.

21. Fritsch SD, Weichhart T. Effects of interferons and viruses on metabolism. Front Immunol. 2016;7:630. https://doi.org/10. 3389/fimmu.2016.00630.

22. Kamada R, Yang W, Zhang Y, Patel MC, Yang Y, Ouda R, et al. Interferon stimulation creates chromatin marks and establishes transcriptional memory. Proc Natl Acad Sci U S A. 2018;115:E9162-71. https://doi.org/10.1073/pnas.1720930115.

23. Maslov S, Sneppen K. Specificity and stability in topology of protein networks. Science. 2002;296:910-3. https://doi.org/ 10.1126/science.1065103.

24. Verleyen W, Ballouz S, Gillis J. Positive and negative forms of replicability in gene network analysis. Bioinformatics. 2016; 32:1065-73. https://doi.org/10.1093/bioinformatics/btv734.

25. Gillis J, Pavlidis P. The impact of multifunctional genes on "guilt by association" analysis. PLoS One. 2011;6:e17258. https://doi.org/10.1371/journal.pone.0017258.

26. Andersen JS, Wilkinson CJ, Mayor T, Mortensen P, Nigg EA, Mann M. Proteomic characterization of the human centrosome by protein correlation profiling. Nature. 2003;426:570-4. https://doi.org/10.1038/nature02166.

27. Foster $L$, de Hoog CL, Zhang Y, Zhang Y, Xie X, Mootha VK, et al. A mammalian organelle map by protein correlation profiling. Cell. 2006;125:187-99. https://doi.org/10.1016/j.cell.2006.03.022.

28. Giurgiu M, Reinhard J, Brauner B, Dunger-Kaltenbach I, Fobo G, Frishman G, et al. CORUM: the comprehensive resource of mammalian protein complexes-2019. Nucleic Acids Res. 2019;47:D559-63. https://doi.org/10.1093/nar/gky973.

29. Cox J, Mann M. MaxQuant enables high peptide identification rates, individualized p.p.b.-range mass accuracies and proteome-wide protein quantification. Nat Biotechnol. 2008;26:1367-72. https://doi.org/10.1038/nbt.1511.

30. Noble WS. Mass spectrometrists should search only for peptides they care about. Nat Methods. 2015;12:605-8. https:// doi.org/10.1038/nmeth.3450.

31. Ezkurdia I, Vázquez J, Valencia A, Tress M. Analyzing the first drafts of the human proteome. J Proteome Res. 2014;13: 3854-5. https://doi.org/10.1021/pr500572z.

32. Stacey RG, Skinnider MA, Scott NE, Foster L. A rapid and accurate approach for prediction of interactomes from coelution data (PrlnCE). BMC Bioinformatics. 2017;18:457. https://doi.org/10.1186/s12859-017-1865-8.

33. Skinnider MA, Stacey RG, Scott NE, Kristensen A, Foster LJ. PrInCE: Predicting Interactomes from Co-Elution (R package). Bioconductor. 2019. doi:https://doi.org/10.18129/b9.bioc.prince.

34. Havugimana PC, Hart GT, Nepusz T, Yang H, Turinsky AL, Li Z, et al. A census of human soluble protein complexes. Cell. 2012;150:1068-81. https://doi.org/10.1016/j.cell.2012.08.011.

35. Wan C, Borgeson B, Phanse S, Tu F, Drew K, Clark G, et al. Panorama of ancient metazoan macromolecular complexes. Nature. 2015;525:339-44. https://doi.org/10.1038/nature14877.

36. Kastritis PL, O'Reilly FJ, Bock T, Li Y, Rogon MZ, Buczak K, et al. Capturing protein communities by structural proteomics in a thermophilic eukaryote. Mol Syst Biol. 2017;13:936. https://doi.org/10.15252/msb.20167412.

37. Hu LZ, Goebels F, Tan JH, Wolf E, Kuzmanov U, Wan C, et al. EPIC: software toolkit for elution profile-based inference of protein complexes. Nat Methods. 2019;16:737-42. https://doi.org/10.1038/s41592-019-0461-4.

38. Skinnider MA, Stacey RG, Foster L. Genomic data integration systematically biases interactome mapping. PLoS Comput Biol. 2018;14:e1006474. https://doi.org/10.1371/journal.pcbi.1006474.

39. Mosca R, Céol A, Stein A, Olivella R, Aloy P. 3did: a catalog of domain-based interactions of known three-dimensional structure. Nucleic Acids Res. 2014;42(Database issue):D374-9. https://doi.org/10.1093/nar/gkt887.

40. Stacey RG, Skinnider MA, Chik JHL, Foster LJ. Context-specific interactions in literature-curated protein interaction databases. BMC Genomics. 2018;19:758. https://doi.org/10.1186/s12864-018-5139-2.

41. Breuer K, Foroushani AK, Laird MR, Chen C, Sribnaia A, Lo R, et al. InnateDB: systems biology of innate immunity and beyond--recent updates and continuing curation. Nucleic Acids Res. 2013;41(Database issue):D1228-33. https://doi.org/ 10.1093/nar/gks1147.

42. Haynes WA, Vallania F, Liu C, Bongen E, Tomczak A, Andres-Terrè M, et al. Empowering multi-cohort gene expression analysis to increase reproducibility. Pac Symp Biocomput. 2017;22:144-53. https://doi.org/10.1142/9789813207813_0015.

43. Sweeney TE, Haynes WA, Vallania F, loannidis JP, Khatri P. Methods to increase reproducibility in differential gene expression via meta-analysis. Nucleic Acids Res. 2017;45:e1. https://doi.org/10.1093/nar/gkw797.

44. Lindblad-Toh K, Garber M, Zuk O, Lin MF, Parker BJ, Washietl S, et al. A high-resolution map of human evolutionary constraint using 29 mammals. Nature. 2011;478:476-82. https://doi.org/10.1038/nature10530.

45. Yue F, Cheng Y, Breschi A, Vierstra J, Wu W, Ryba T, et al. A comparative encyclopedia of DNA elements in the mouse genome. Nature. 2014;515:355-64. https://doi.org/10.1038/nature13992.

46. Lilue J, Doran AG, Fiddes IT, Abrudan M, Armstrong J, Bennett R, et al. Sixteen diverse laboratory mouse reference genomes define strain-specific haplotypes and novel functional loci. Nat Genet. 2018;50:1574-83. https://doi.org/10. 1038/s41588-018-0223-8.

47. Bandyopadhyay $S$, Mehta M, Kuo D, Sung M-K, Chuang $R$, Jaehnig EJ, et al. Rewiring of genetic networks in response to DNA damage. Science. 2010;330:1385-9. https://doi.org/10.1126/science.1195618.

48. Sonnhammer ELL, Östlund G. InParanoid 8: orthology analysis between 273 proteomes, mostly eukaryotic. Nucleic Acids Res. 2015;43(Database issue):D234-9. https://doi.org/10.1093/nar/gku1203.

49. Lek M, Karczewski KJ, Minikel EV, Samocha KE, Banks E, Fennell T, et al. Analysis of protein-coding genetic variation in 60,706 humans. Nature. 2016;536:285-91. https://doi.org/10.1038/nature19057.

50. Venkatesan K, Rual J-F, Vazquez A, Stelzl U, Lemmens I, Hirozane-Kishikawa T, et al. An empirical framework for binary interactome mapping. Nat Methods. 2009:6:83-90. https://doi.org/10.1038/nmeth.1280.

51. Konagurthu AS, Lesk AM. On the origin of distribution patterns of motifs in biological networks. BMC Syst Biol. 2008;2: 73. https://doi.org/10.1186/1752-0509-2-73

52. Merico D, Isserlin R, Stueker O, Emili A, Bader GD. Enrichment map: a network-based method for gene-set enrichment visualization and interpretation. PLoS One. 2010;5:e13984. https://doi.org/10.1371/journal.pone. 0013984.

53. Smith JL, Jeng S, McWeeney SK, Hirsch AJ. A MicroRNA screen identifies the Wnt signaling pathway as a regulator of the interferon response during flavivirus infection. J Virol. 2017;91. https://doi.org/10.1128/JVI.02388-16. 
54. Nava P, Koch S, Laukoetter MG, Lee WY, Kolegraff $K$, Capaldo $C T$, et al. Interferon-gamma regulates intestinal epithelial homeostasis through converging beta-catenin signaling pathways. Immunity. 2010;32:392-402. https://doi.org/10.1016/j. immuni.2010.03.001.

55. Shalek AK, Satija R, Adiconis X, Gertner RS, Gaublomme JT, Raychowdhury R, et al. Single-cell transcriptomics reveals bimodality in expression and splicing in immune cells. Nature. 2013;498:236-40. https://doi.org/10.1038/nature12172.

56. Lim E, Vaillant F, Wu D, Forrest NC, Pal B, Hart AH, et al. Aberrant luminal progenitors as the candidate target population for basal tumor development in BRCA1 mutation carriers. Nat Med. 2009;15:907-13. https://doi.org/10.1038/nm.2000.

57. Mellacheruvu D, Wright Z, Couzens AL, Lambert J-P, St-Denis NA, Li T, et al. The CRAPome: a contaminant repository for affinity purification-mass spectrometry data. Nat Methods. 2013;10:730-6. https://doi.org/10.1038/nmeth.2557.

58. Chen J, Shpall RL, Meyerdierks A, Hagemeier M, Böttger EC, Naumovski L. Interferon-inducible Myc/STAT-interacting protein Nmi associates with IFP 35 into a high molecular mass complex and inhibits proteasome-mediated degradation of IFP 35. J Biol Chem. 2000;275:36278-84. https://doi.org/10.1074/jbc.M006975200.

59. Zhou X, Liao J, Meyerdierks A, Feng L, Naumovski L, Bottger EC, et al. Interferon-alpha induces nmi-IFP35 heterodimeric complex formation that is affected by the phosphorylation of IFP35. J Biol Chem. 2000;275:21364-71. https://doi.org/10. 1074/jbc.M003177200.

60. Zhu M, John S, Berg M, Leonard WJ. Functional association of Nmi with Stat5 and Stat1 in IL-2- and IFNgammamediated signaling. Cell. 1999:96:121-30.

61. Das A, Dinh PX, Panda D, Pattnaik AK. Interferon-inducible protein IFI35 negatively regulates RIG-I antiviral signaling and supports vesicular stomatitis virus replication. J Virol. 2014;88:3103-13. https://doi.org/10.1128/JVI.03202-13.

62. Das A, Dinh PX, Pattnaik AK. Trim21 regulates Nmi-IFl35 complex-mediated inhibition of innate antiviral response. Virology. 2015;485:383-92. https://doi.org/10.1016/j.virol.2015.08.013.

63. Meyerdierks A, Denecke B, Rohde M, Taparowsky EJ, Böttger EC. A cytoplasmic structure resembling large protein aggregates induced by interferons. J Histochem Cytochem. 1999:47:169-82. https://doi.org/10.1177/ 002215549904700206.

64. Chen J, Naumovski L. Intracellular redistribution of interferon-inducible proteins Nmi and IFP 35 in apoptotic cells. J Interf Cytokine Res. 2002;22:237-43. https://doi.org/10.1089/107999002753536211.

65. Xue S, Barna M. Specialized ribosomes: a new frontier in gene regulation and organismal biology. Nat Rev Mol Cell Biol. 2012;13:355-69. https://doi.org/10.1038/nrm3359.

66. Genuth NR, Barna M. The discovery of ribosome heterogeneity and its implications for gene regulation and organismal life. Mol Cell. 2018;71:364-74. https://doi.org/10.1016/j.molcel.2018.07.018.

67. Kondrashov N, Pusic A, Stumpf CR, Shimizu K, Hsieh AC, Ishijima J, et al. Ribosome-mediated specificity in Hox mRNA translation and vertebrate tissue patterning. Cell. 2011;145:383-97. https://doi.org/10.1016/j.cell.2011.03.028.

68. Xue S, Tian S, Fujii K, Kladwang W, Das R, Barna M. RNA regulons in Hox 5' UTRs confer ribosome specificity to gene regulation. Nature. 2015;517:33-8. https://doi.org/10.1038/nature14010.

69. Shi Z, Fujii K, Kovary KM, Genuth NR, Röst HL, Teruel MN, et al. Heterogeneous ribosomes preferentially translate distinct subpools of mRNAs genome-wide. Mol Cell. 2017;67:71-83.e7. https://doi.org/10.1016/j.molcel.2017.05.021.

70. Uhlén M, Fagerberg L, Hallström BM, Lindskog C, Oksvold P, Mardinoglu A, et al. Proteomics. Tissue-based map of the human proteome. Science. 2015;347:1260419. https://doi.org/10.1126/science.1260419.

71. Lizio M, Harshbarger J, Abugessaisa I, Noguchi S, Kondo A, Severin J, et al. Update of the FANTOM web resource: high resolution transcriptome of diverse cell types in mammals. Nucleic Acids Res. 2017;45:D737-43. https://doi.org/10.1093/ nar/gkw995.

72. Mills EW, Green R. Ribosomopathies: there's strength in numbers. Science. 2017;358. https://doi.org/10.1126/science. $\operatorname{aan} 2755$.

73. Zanini F, Robinson ML, Croote D, Sahoo MK, Sanz AM, Ortiz-Lasso E, et al. Virus-inclusive single-cell RNA sequencing reveals the molecular signature of progression to severe dengue. Proc Natl Acad Sci U S A. 2018;115:E12363-9. https:// doi.org/10.1073/pnas.1813819115

74. Steuerman Y, Cohen M, Peshes-Yaloz N, Valadarsky L, Cohn O, David E, et al. Dissection of influenza infection in vivo by single-cell RNA sequencing. Cell Syst. 2018;6:679-91.e4. https://doi.org/10.1016/j.cels.2018.05.008.

75. Hein MY, Weissman JS. Functional single-cell genomics of human cytomegalovirus infection. BioRxiv. 2019. https://doi. org/10.1101/775080.

76. de Weerd NA, Nguyen T. The interferons and their receptors--distribution and regulation. Immunol Cell Biol. 2012;90: 483-91. https://doi.org/10.1038/icb.2012.9.

77. Scott NE, Rogers LD, Prudova A, Brown NF, Fortelny N, Overall CM, et al. Interactome disassembly during apoptosis occurs independent of caspase cleavage. Mol Syst Biol. 2017;13:906. https://doi.org/10.15252/msb.20167067.

78. Werner JN, Chen EY, Guberman JM, Zippilli AR, Irgon JJ, Gitai Z. Quantitative genome-scale analysis of protein localization in an asymmetric bacterium. Proc Natl Acad Sci U S A. 2009;106:7858-63. https://doi.org/10.1073/pnas. 0901781106.

79. Becher I, Andrés-Pons A, Romanov N, Stein F, Schramm M, Baudin F, et al. Pervasive protein thermal stability variation during the cell cycle. Cell. 2018;173:1495-507.e18. https://doi.org/10.1016/j.cell.2018.03.053.

80. Dai L, Zhao T, Bisteau X, Sun W, Prabhu N, Lim YT, et al. Modulation of protein-interaction states through the cell cycle. Cell. 2018;173:1481-94.e13. https://doi.org/10.1016/j.cell.2018.03.065.

81. Tan CSH, Go KD, Bisteau X, Dai L, Yong CH, Prabhu N, et al. Thermal proximity coaggregation for system-wide profiling of protein complex dynamics in cells. Science. 2018;359:1170-7. https://doi.org/10.1126/science.aan0346.

82. Skinnider MA, Scott NE, Prudova A, Stoynov N, Stacey RG, Gsponer J, et al. An atlas of protein-protein interactions across mammalian tissues. BioRxiv. 2018. https://doi.org/10.1101/351247.

83. De Las RJ, Fontanillo C. Protein-protein interactions essentials: key concepts to building and analyzing interactome networks. PLoS Comput Biol. 2010;6:e1000807. https://doi.org/10.1371/journal.pcbi.1000807.

84. Wodak SJ, Vlasblom J, Turinsky AL, Pu S. Protein-protein interaction networks: the puzzling riches. Curr Opin Struct Biol. 2013;23:941-53. https://doi.org/10.1016/j.sbi.2013.08.002.

85. Cusick ME, Yu H, Smolyar A, Venkatesan K, Carvunis A-R, Simonis N, et al. Literature-curated protein interaction datasets. Nat Methods. 2009;6:39-46. https://doi.org/10.1038/nmeth.1284. 
86. Salwinski L, Licata L, Winter A, Thorneycroft D, Khadake J, Ceol A, et al. Recurated protein interaction datasets. Nat Methods. 2009;6:860-1. https://doi.org/10.1038/nmeth1209-860.

87. Jensen $L$, Bork P. Biochemistry. Not comparable, but complementary. Science. 2008;322:56-7. https://doi.org/10.1126/ science.1164801.

88. Drew K, Müller CL, Bonneau R, Marcotte EM. Identifying direct contacts between protein complex subunits from their conditional dependence in proteomics datasets. PLoS Comput Biol. 2017;13:e1005625. https://doi.org/10.1371/journal. pcbi.1005625.

89. Taşan M, Musso G, Hao T, Vidal M, MacRae CA, Roth FP. Selecting causal genes from genome-wide association studies via functionally coherent subnetworks. Nat Methods. 2015;12:154-9. https://doi.org/10.1038/nmeth.3215.

90. Köhler S, Bauer S, Horn D, Robinson PN. Walking the interactome for prioritization of candidate disease genes. Am J Hum Genet. 2008;82:949-58. https://doi.org/10.1016/j.ajhg.2008.02.013.

91. Rappsilber J, Mann M, Ishihama Y. Protocol for micro-purification, enrichment, pre-fractionation and storage of peptides for proteomics using StageTips. Nat Protoc. 2007;2:1896-906. https://doi.org/10.1038/nprot.2007.261.

92. Beck S, Michalski A, Raether O, Lubeck M, Kaspar S, Goedecke N, et al. The impact II, a very high-resolution quadrupole time-of-flight instrument (QTOF) for deep shotgun proteomics. Mol Cell Proteomics. 2015;14:2014-29. https://doi.org/10 1074/mcp.M114.047407.

93. Meier F, Brunner A-D, Koch S, Koch H, Lubeck M, Krause M, et al. Online parallel accumulation-serial fragmentation (PASEF) with a novel trapped ion mobility mass spectrometer. Mol Cell Proteomics. 2018;17:2534-45. https://doi.org/10. 1074/mcp.TIR118.000900

94. Cox J, Hein MY, Luber CA, Paron I, Nagaraj N, Mann M. Accurate proteome-wide label-free quantification by delayed normalization and maximal peptide ratio extraction, termed MaxLFQ. Mol Cell Proteomics. 2014;13:2513-26. https://doi. org/10.1074/mcp.M113.031591.

95. Tyanova S, Mann M, Cox J. MaxQuant for in-depth analysis of large SILAC datasets. Methods Mol Biol. 2014;1188:351-64. https://doi.org/10.1007/978-1-4939-1142-4_24.

96. UniProt CT. UniProt: the universal protein knowledgebase. Nucleic Acids Res. 2018;46:2699. https://doi.org/10.1093/nar/ gky092.

97. Tyanova S, Temu T, Sinitcyn P, Carlson A, Hein MY, Geiger T, et al. The Perseus computational platform for comprehensive analysis of (prote)omics data. Nat Methods. 2016;13:731-40. https://doi.org/10.1038/nmeth.3901.

98. Ritchie ME, Phipson B, Wu D, Hu Y, Law CW, Shi W, et al. limma powers differential expression analyses for RNAsequencing and microarray studies. Nucleic Acids Res. 2015;43:e47. https://doi.org/10.1093/nar/gkv007.

99. Alexa A, Rahnenführer J, Lengauer T. Improved scoring of functional groups from gene expression data by decorrelating GO graph structure. Bioinformatics. 2006;22:1600-7. https://doi.org/10.1093/bioinformatics/btl140.

100. Falcon S, Gentleman R. Using GOstats to test gene lists for GO term association. Bioinformatics. 2007;23:257-8. https:// doi.org/10.1093/bioinformatics/bt|567.

101. Ray J, Pinar A, Seshadhri C. Are we there yet? When to stop a Markov chain while generating random graphs. In: Algorithms and models for the web graph. Bonato A, Janssen J, editors. Berlin: Springer Berlin Heidelberg; 2012. p. 15364. doi:https://doi.org/10.1007/978-3-642-30541-2 12

102. Hurvich CM, Tsai C-L. Regression and time series model selection in small samples. Biometrika. 1989;76:297-307. https:// doi.org/10.1093/biomet/76.2.297.

103. Ashburner M, Ball CA, Blake JA, Botstein D, Butler H, Cherry JM, et al. Gene ontology: tool for the unification of biology. Gene Ontol Consortium Nat Genet. 2000;25:25-9. https://doi.org/10.1038/75556.

104. Huntley RP, Sawford T, Mutowo-Meullenet P, Shypitsyna A, Bonilla C, Martin MJ, et al. The GOA database: gene ontology annotation updates for 2015. Nucleic Acids Res. 2015;43(Database issue):D1057-63. https://doi.org/10.1093/nar/gku1113.

105. Greene D, Richardson S, Turro E. ontologyX: a suite of R packages for working with ontological data. Bioinformatics. 2017;33:1104-6. https://doi.org/10.1093/bioinformatics/btw763.

106. Eppig JT, Blake JA, Bult CJ, Kadin JA, Richardson JE, Mouse Genome Database Group. The Mouse Genome Database (MGD): facilitating mouse as a model for human biology and disease. Nucleic Acids Res. 2015;43(Database issue):D72636. https://doi.org/10.1093/nar/gku967.

107. Kim M-S, Pinto SM, Getnet D, Nirujogi RS, Manda SS, Chaerkady R, et al. A draft map of the human proteome. Nature. 2014;509:575-81. https://doi.org/10.1038/nature13302.

108. Fortelny N, Butler GS, Overall CM, Pavlidis P. Protease-inhibitor interaction predictions: lessons on the complexity of protein-protein interactions. Mol Cell Proteomics. 2017;16:1038-51. https://doi.org/10.1074/mcp.M116.065706.

109. Alfarano C, Andrade CE, Anthony K, Bahroos N, Bajec M, Bantoft K, et al. The biomolecular interaction network database and related tools 2005 update. Nucleic Acids Res. 2005;33(Database issue):D418-24. https://doi.org/10.1093/nar/gki051.

110. Chatr-Aryamontri A, Oughtred R, Boucher L, Rust J, Chang C, Kolas NK, et al. The BioGRID interaction database: 2017 update. Nucleic Acids Res. 2017;45:D369-79. https://doi.org/10.1093/nar/gkw1102.

111. Salwinski L, Miller CS, Smith AJ, Pettit FK, Bowie JU, Eisenberg D. The database of interacting proteins: 2004 update. Nucleic Acids Res. 2004;32(Database issue):D449-51. https://doi.org/10.1093/nar/gkh086.

112. Das J, Yu H. HINT: high-quality protein interactomes and their applications in understanding human disease. BMC Syst Biol. 2012;6:92. https://doi.org/10.1186/1752-0509-6-92.

113. Alanis-Lobato G, Andrade-Navarro MA, Schaefer MH. HIPPIE v2.0: enhancing meaningfulness and reliability of proteinprotein interaction networks. Nucleic Acids Res. 2017;45:D408-14. https://doi.org/10.1093/nar/gkw985.

114. Keshava Prasad TS, Goel R, Kandasamy K, Keerthikumar S, Kumar S, Mathivanan S, et al. Human protein reference database--2009 update. Nucleic Acids Res. 2009;37(Database issue):D767-72. https://doi.org/10.1093/nar/gkn892.

115. Kotlyar M, Pastrello C, Sheahan N, Jurisica I. Integrated interactions database: tissue-specific view of the human and model organism interactomes. Nucleic Acids Res. 2016;44:D536-41. https://doi.org/10.1093/nar/gkv1115.

116. Launay G, Salza R, Multedo D, Thierry-Mieg N, Ricard-Blum S. MatrixDB, the extracellular matrix interaction database: updated content, a new navigator and expanded functionalities. Nucleic Acids Res. 2015;43(Database issue):D321-7. https://doi.org/10.1093/nar/gku1091.

117. Calderone A, Castagnoli L, Cesareni G. mentha: a resource for browsing integrated protein-interaction networks. Nat Methods. 2013;10:690-1. https://doi.org/10.1038/nmeth.2561. 
118. Licata L, Briganti L, Peluso D, Perfetto L, lannuccelli M, Galeota E, et al. MINT, the molecular interaction database: 2012 update. Nucleic Acids Res. 2012;40(Database issue):D857-61. https://doi.org/10.1093/nar/gkr930.

119. Pagel P, Kovac S, Oesterheld M, Brauner B, Dunger-Kaltenbach I, Frishman G, et al. The MIPS mammalian protein-protein interaction database. Bioinformatics. 2005;21:832-4. https://doi.org/10.1093/bioinformatics/bti115.

120. Kandasamy K, Mohan SS, Raju R, Keerthikumar S, Kumar GSS, Venugopal AK, et al. NetPath: a public resource of curated signal transduction pathways. Genome Biol. 2010;11:R3. https://doi.org/10.1186/gb-2010-11-1-r3.

121. Cowley MJ, Pinese M, Kassahn KS, Waddell N, Pearson JV, Grimmond SM, et al. PINA v2.0: mining interactome modules. Nucleic Acids Res. 2012;40(Database issue):D862-5. https://doi.org/10.1093/nar/gkr967.

122. Fabregat A, Jupe S, Matthews L, Sidiropoulos K, Gillespie M, Garapati P, et al. The reactome pathway knowledgebase. Nucleic Acids Res. 2018;46:D649-55. https://doi.org/10.1093/nar/gkx1132.

123. Kutmon M, Riutta A, Nunes N, Hanspers K, Willighagen EL, Bohler A, et al. WikiPathways: capturing the full diversity of pathway knowledge. Nucleic Acids Res. 2016;44:D488-94. https://doi.org/10.1093/nar/gkv1024.

124. Tyner S, Briatte F, Hofmann H. Network visualization with ggplot2. R J. 2017:9:27. https://doi.org/10.32614/RJ-2017-023.

125. Fruchterman TMJ, Reingold EM. Graph drawing by force-directed placement. Softw: Pract Exper. 1991;21:1129-64. https://doi.org/10.1002/spe.4380211102.

126. Zerbino DR, Achuthan P, Akanni W, Amode MR, Barrell D, Bhai J, et al. Ensembl 2018. Nucleic Acids Res. 2018;46:D75461. https://doi.org/10.1093/nar/gkx1098.

127. Kim S. ppcor: an R package for a fast calculation to semi-partial correlation coefficients. Commun Stat Appl Methods. 2015;22:665-74. https://doi.org/10.5351/CSAM.2015.22.6.665

128. Subramanian A, Tamayo P, Mootha VK, Mukherjee S, Ebert BL, Gillette MA, et al. Gene set enrichment analysis: a knowledge-based approach for interpreting genome-wide expression profiles. Proc Natl Acad Sci U S A. 2005;102: 15545-50. https://doi.org/10.1073/pnas.0506580102.

129. Sergushichev A. An algorithm for fast preranked gene set enrichment analysis using cumulative statistic calculation. BioRxiv. 2016. https://doi.org/10.1101/060012.

130. Vizcaíno JA, Deutsch EW, Wang R, Csordas A, Reisinger F, Ríos D, et al. ProteomeXchange provides globally coordinated proteomics data submission and dissemination. Nat Biotechnol. 2014;32:223-6. https://doi.org/10.1038/nbt.2839.

131. Vizcaíno JA, Csordas A, del-Toro N, Dianes JA, Griss J, Lavidas I, et al. 2016 update of the PRIDE database and its related tools. Nucleic Acids Res. 2016:44:D447-56. doi:https://doi.org/10.1093/nar/gkv1 145.

132. Kerr CH, Skinnider MA, Andrews DDT, Madero AM, Chan QWT, Stacey RG, Stoynov N, Jan E, and Foster LJ. Dynamic rewiring of the human interactome by interferon signaling. Proteomics Identification Database. http://proteomecentral. proteomexchange.org/cgi/GetDataset?ID=PXD013809 (2020).

133. Sarkans U, Gostev M, Athar A, Behrangi E, Melnichuk O, Ali A, et al. The BioStudies database-one stop shop for all data supporting a life sciences study. Nucleic Acids Res. 2018;46:D1266-70. https://doi.org/10.1093/nar/gkx965.

134. Kerr CH, Skinnider MA, Andrews DDT, Madero AM, Chan QWT, Stacey RG, Stoynov N, Jan E, and Foster LJ. Dynamic rewiring of the human interactome by interferon signaling. EMBL Biostudies Database. https://www.ebi.ac.uk/biostudies/ studies/S-BSST254?query=S-BSST254 (2020).

\section{Publisher's Note}

Springer Nature remains neutral with regard to jurisdictional claims in published maps and institutional affiliations.

\section{Ready to submit your research? Choose BMC and benefit from:}

- fast, convenient online submission

- thorough peer review by experienced researchers in your field

- rapid publication on acceptance

- support for research data, including large and complex data types

- gold Open Access which fosters wider collaboration and increased citations

- maximum visibility for your research: over $100 \mathrm{M}$ website views per year

At $B M C$, research is always in progress.

Learn more biomedcentral.com/submissions 